
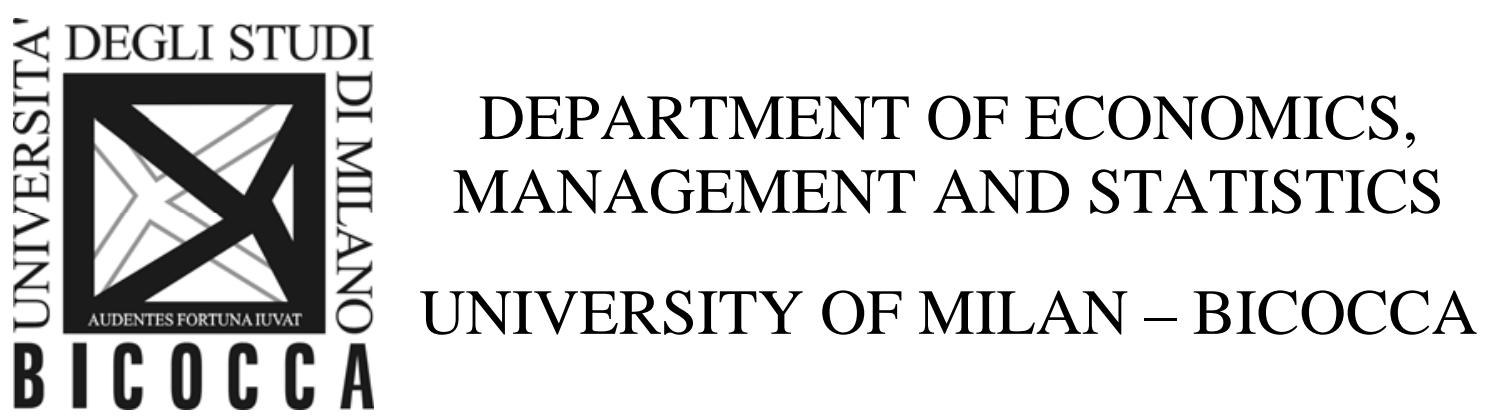

DEMS WORKING PAPER SERIES

\title{
Does it take two to tango? Improving cooperation between the IMF and the World Bank: theory and empirical evidence
}

Silvia Marchesi, Laura Sabani

No. 280 - October 2014

Dipartimento di Economia, Metodi Quantitativi e Strategie di Impresa Università degli Studi di Milano - Bicocca http://dems.unimib.it/ 


\title{
Does it take two to tango? Improving cooperation between the IMF and the World Bank: theory and empirical evidence
}

\author{
Silvia Marchesi* \\ University of Milano Bicocca and Centro Studi Luca d'Agliano \\ Laura Sabani \\ University of Firenze
}

July 2014

\begin{abstract}
In this paper we present a theoretical model which, focusing on the quality of information transmission between the IMF and the WB, analyzes the sources of the expected loss in the overall performance of the two institutions relative to the first best outcome, which is characterized by centralized decision and perfect information. In particular, given the Bank-Fund strong complementarities, we show that strategic communication is indeed the primary source of loss for the two institutions. A testable implication of the model is to relate Bank-Fund's performance to their willingness (or ability) to communicate. We find evidence that a Bank-Fund simultaneous loan is beneficial to growth and, consistently with the theory, such beneficial effect is reduced by factors preventing full communication, such as the degree of Bank-Fund competition and the salience of their private information.
\end{abstract}

Keywords: IMF and WB conditionality, coordination, communication JEL Classification: D83, F33, N2.

\footnotetext{
${ }^{*}$ We thank Axel Dreher, Martin Gassebner, Pietro Gottardi, Rune Hagen, Christopher Kilby, Stephen Knack, Audrey Menard, Chiara Rapallini, Randall Stone and Simone Tedeschi for useful comment and suggestions. We also thank participants at the BBQ Conference (Heidelberg, 2014) and the Political Economy of International Organizations (PEIO) Annual Meeting (Heidelberg and Mannheim, 2013). E-mail adresses: silvia.marchesi@unimib.it; laura.sabani@unifi.it
} 
"While everyone agrees that coordination is necessary, nobody wants to be the one that is coordinated," Joachim Koops (director of the Global Governance Institute, a Brussels-based think-tank, The Economist June 1st 2013)

\section{Introduction}

The International Monetary Fund (IMF) and the World Bank (WB) were originally created as two distinct and independent institutions with complementary tasks and different methods of intervention, within the framework of the Bretton Woods agreement (1944). Over the years, however, their mandates have expanded in response to the changing realities of the global economy and the degree of overlap between the two has increased, leading to more room for both conflict and cooperation. The importance of close collaboration between the Bank and the Fund is now a well recognized fact, which has also periodically been emphasized in a number of official documents. ${ }^{1}$ However, despite a series of declarations and agreements aimed at strengthening Bank-Fund collaboration, it is widely believed that coordination still falls short of what could be rationally expected (Truman, 2006).

The official reports, that have tried to identify guidelines aimed at enhancing cooperation between the Bank and the Fund, have almost unanimously agreed that "information sharing" is the area which still needs to be greatly improved. ${ }^{2}$ This comes as no surprise since successful cooperation does require effective transmission of information (communication) whenever informational asymmetries exist. ${ }^{3}$ Thus, investigating what factors influence the quality and the extent of communication between the Bank and the Fund has now become particularly relevant. Little theoretical and empirical analyses, however, exist about what circumstances may inhibit or encourage Bank-Fund communication.

This paper contributes to fill this gap by opening the "black box" of Bank-Fund interaction. We focus on the problem of information transmission between these two institutions, with communication modeled as cheap talk. ${ }^{4}$ This choice is justified by the fact that, as the reform agenda has deepened to include institutional and social reforms, the collection of specialized

\footnotetext{
${ }^{1}$ As Krueger (1997) puts it: "a strong case can be made that the functions of lending policy advice, training, research and provision of information of both the Bank and the Fund are mutually complementary and that the spillovers from each of the functions to the others are large."

${ }^{2}$ For example, see the Malan Report (2006) and the Joint Management Action Plan on Bank-Fund Collaboration (JMAP) Report (2010).

${ }^{3}$ Although the extent of overlap between the operations of the two organizations have increased over time, they still maintain a strongly specialized expertise in their core areas of intervention: monetary, fiscal, and exchange rate policies for the Fund and policy areas related to development for the Bank. Therefore, each institution bases its decision on specialized information that is only partially overlapping.

${ }^{4}$ Cheap talk consists of costless, non binding, non verifiable messages that can affect receivers' beliefs.
} 
information by the Fund and the Bank has increasingly consisted in acquiring countryspecific inputs (or local knowledge), which are mainly made up of unverifiable information (soft information). ${ }^{5}$ In this context, the existence of incentives conflicts between the Bank and the Fund might hinder credible information transmission, as shown in the Crawford and Sobel (1982) seminal paper on strategic information transmission. Assuming a two-sided incomplete information framework, this paper explores the incentives of the IMF and the WB to communicate information under misaligned interests.

Even though our analysis could be easily applied to the interaction of many types of international organizations, in this paper we have chosen to focus only on the IMF-WB interaction for two main reasons. Firstly, since the ' 80 s the degree of overlap between the two institutions has been steadily increasing making their communication increasingly important. The second reason is that data availability makes relatively easier to test some of the empirical predictions of the theoretical model, while it would be more difficult to find comparably data in the case of other organizations.

In this paper both the Fund and the Bank decision making involves a trade off between the need of coordinating their policy decisions and the need to adapt to "local conditions," as revealed by each organization's specialized information. More specifically, each institution must balance the benefit of setting its policy decision close to the other, with the benefit of setting its decision close to its own local condition. Moreover, consistently with the current governance structure, we assume that each institution only cares about its own performance, which means that neither the Fund nor the Bank internalizes how their own policy decisions may affect the other institution's performance (the so called own-institution bias).

We study the model equilibria when the Fund and the Bank first learn their local conditions, then communicate with each other, and finally take their decisions. In this setting equilibria are shown to be partition equilibria, where each sender only indicates to which interval the realized state that he observes belongs, as in standard cheap talk models. In other words, information transmission is distorted, since both actors use communication strategically to influence decision making to their favour. By comparing our results to the first best outcome, which is characterized by perfect symmetric information and centralized decision making, we show that the expected loss (relative to the first best) is made up of two components: a "selfishness" loss, and a "strategic communication" loss. The first component depends on the own-institution bias, leading to excessively uncoordinated policy decisions. The second component is due to strategic communication that worsens coordination failures owing to

\footnotetext{
${ }^{5}$ For more details on the importance of context-specific knowledge for reforms design see, among others, Dixit (2009), Easterly (2006, 2008), Rajan (2008) and Marchesi et al. (2011).
} 
decentralized decision making. When the need of coordination is very high (as it typically is the case of Bank-Fund operations, given their strong complementarities), we find that strategic communication becomes the primary source of loss relative to the first best outcome. In particular, we identify two main factors playing an important role in determining the relevance of such loss: the level of competition between the two institutions (or "domain dissent"), and the relevance of their specialized local information relative to their general expertise as multilateral organizations.

A testable implication of the model is to relate a measure of Bank-Fund's performance to some variables which can be interpreted as proxy of their willingness (or ability) to communicate. As a measure of Bank-Fund's performance we take the impact of a Bank-Fund simultaneous loan on recipient country's growth and, in accordance with Marchesi and Sirtori (2011), we find evidence that Bank-Fund simultaneous loan is beneficial to growth. Furthermore, consistently with the theoretical results, we find that such beneficial effect is reduced by factors preventing full communication, such as the degree of Bank-Fund competition and the salience of their private information.

The paper is organized as follows. Section 2 offers some institutional information regarding the overlapping responsibilities of the IMF and the WB. Section 3 briefly presents the related literature. Section 4 describes the theoretical basis for analyzing Bank-Fund communication. Section 5 discusses normative and testable implications of the theoretical model. Section 6 turns to the empirical model and section 7 describes the data while the results are presented in section 8. Section 9 contains some robustness check and, finally, section 10 concludes.

\section{The IMF and the World Bank: synergies and conflict}

The World Bank and the IMF were created as two distinct and independent institutions with different tasks and methods of intervention, within the framework of the Bretton Woods agreement (1944). Up to the 1980s, the division of labor between the Fund and the Bank had been relatively straightforward. While the Fund's orientation was towards short-run macroeconomic stability, the Bank was oriented towards long-run development programs. At the same time the existence of synergies between the two institutions had also been recognized. Such synergies, however, became more important during the 70's and the 80's when, on the one hand, the IMF started to complement demand management policies by supply side policies and, on the other, the World Bank changed its policy towards a more explicit recognition of the importance of macroeconomic policies besides the traditional project and sector lend- 
ing. ${ }^{6}$ Moreover, during the 1980s, the Fund's lending became more concessional and related to structural matters and increasingly focused on lower income countries, those typically "served" by the Bank.

The first step towards a formal recognition of the importance of cooperation between the IMF and the World Bank was already made in 1966 with an agreement which explicitly laid out the primary responsibilities of each organization and the procedures for the two to work together (Boughton 2001). ${ }^{7}$ Then, in 1974, a joint ministerial committee of the Boards of Governors of the Bank and the Fund - the Development Committee (DC) - was established, in charge of assuring high-level coordination and facilitating intergovernmental consensus-building on development issues.

Lately, in 1989, a Concordat was signed by the IMF and the World Bank in which a vast area of overlapping responsibilities was explicitly identified. In this common area, cooperation should have been pursued and strengthened: to this scope the Concordat did define guidelines and terms of the World Bank-Fund interaction, and the mechanisms for resolving potential conflicts between the sister organizations. Both institutions committed themselves to systematically exchange information concerning low and middle-income countries. Moreover, the Concordat encouraged them to exchange this information not only within their decision bodies, but also at the level of the operative staff. We should emphasize that the Concordat was motivated by the public nature of the disagreement between the Fund and the Bank about Argentina, in 1988. At that time, the rules on collaboration broke down when the World Bank announced a new loan to the country, before the IMF mission had completed its negotiations with the Argentinian authorities. This circumstance forced the two organizations to come up with a new agreement to guide collaboration (Wood, 2006).

Later on, in 1998, during the Asian Crisis, a new episode of disagreement promoted the issuing of a joint statement by the Bank president and the Fund managing director on BankFund collaboration (e.g., see Mallaby 2004). In light of the greater overlap in operations, the leaders of the two organizations reaffirmed that a better collaboration was needed.

Despite all these official documents aimed at strengthening Bank-Fund cooperation, operations in middle-income countries are not yet guided by any formal collaborative vehicle. As

\footnotetext{
${ }^{6}$ Between 1980 and 1984 energy prices were addressed in $46 \%$ of Fund supported programs, the mobilization of domestic savings in $54 \%$ investment planning and execution in $37 \%$. These were areas of primary responsibility of the Bank. Similarly the Bank was increasingly concerned with many variables central to Fund stabilization program (Feinberg 1988).

${ }^{7}$ According to the Dual memoranda of December 1966, the need for collaboration is made explicit by giving numerous examples of overlapping responsibilities: the structure and functioning of financial institutions, the adequacy of money and capital markets, the actual and potential capacity of a country to generate domestic savings, the implications of development programs for the internal and external financial position of a country (Gold 1982).
} 
a result, the Bank and the Fund cooperation hinges critically on discretional communication at the staff level. The case is different for low income countries. With the creation of the Structural Adjustment Facility (SAF) and the Enhanced Structural Adjustment Facility (ESAF), later renamed as the Poverty Reduction and Growth Facility (PRGF), structural adjustment has served to create an important area of overlap between the Bank and the Fund. ${ }^{8}$ To access this program the country has to elaborate a policy framework paper, that is the Poverty Reduction Strategy Paper (PRSPs), jointly with the staff of the Fund and the Bank. The process of drafting the PRSPs was designed to ensure the consistency of the Bank's and the Fund's stances, by encouraging them to develop a common view on the appropriate policy advice for the country. ${ }^{9}$

Despite good intentions PRSPs revealed some weaknesses such as the asymmetry in the documents' operational importance in each organization, the lack of specificity in outlining policy targets, and the failure to effectively engage the borrowing government in the process. Most notably, this latter weakness with the PFP process underscored the need for more substantial country involvement and pushed the Bank and the Fund to acknowledge country ownership as an emerging priority of development cooperation. By many standards, country ownership had come to be considered an important component of successful poverty reduction and development (IMF and World Bank 2001).

More recently, in 2007 the World Bank and the Fund signed a Joint Management Action Plan, which sets concrete steps to improve the culture of cooperation between the two institutions, emphasizing, on the one hand, that duplicate functions represent a waste of resources for both institutions and, on the other, that uncoordinated policy prescriptions can make it harder for recipients dealing with adjustment programs. The Plan calls for an improvement of coordination and communication and it also recommends to translate identified goodpractices concerning interaction into standard practices.

The issue of Fund Bank coordination is still debated nowadays and far form being settled. For example, the forthcoming IMF review on conditionality is expected to contain a fair amount of discussion about coordination with the World Bank. This is going to be crucial especially for middle income countries whose operations are not guided by any formal process, like the

\footnotetext{
${ }^{8}$ In January 2010, three types of loans were created under the new Poverty Reduction and Growth Trust (PRGT) as part of a broader reform: the Extended Credit Facility (ECF), the Rapid Credit Facility (RCF) and the Standby Credit Facility (SCF). In particular, the ECF succeeds the PRGF as the Fund's main tool for providing medium-term support.

${ }^{9}$ In the same year, the Heavily Indebted Poor Countries (HIPC) initiative was enhanced as a direct outcome of a comprehensive review carried out by the International Development Association (IDA) and the IMF. The initiative entails a coordinated commitment to reduce and forgive large volumes of debt to the poorest and most indebted countries.
} 
PRSP or the related facilities in the two organizations.

\section{Related literature}

This paper is related to three strands of literature. The first is the cheap talk literature building on Crawford and Sobel (1982, hereafter CS) $\cdot{ }^{10}$ More specifically, the paper is related to the literature on coordination in organizations under distributed information (Alonso, Dessein and Matouschek 2008, hereafter ADM; Rantakari 2008). These authors address the problem of an organization in which two operating divisions (managers) should adapt to local conditions but also coordinate with each other and their results confirm the general wisdom that when coordination needs are relevant, a centralized structure in which decision rights are allocated to an headquarter, should be preferred, although adaptation to local conditions will be always less satisfactory than in a decentralized structure. In this paper we apply the analysis of ADM and Rantakari (2008) to analyze Bank-Fund communication.

The second stream of literature which we relate to is primarily concerned with the governance of the IFIs. While there are many papers dealing with both the IMF and the WB individually, to the best of our knowledge, there is no contribution addressing theoretically what factors may inhibit or encourage cooperation between the IMF and the WB. ${ }^{11}$ Conversely, on the empirical side, Fabricius (2007), drawing on field research conducted in Ghana, Pakistan, Peru, and Vietnam, over the 1980-96 period, has tried to identify empirically the conditions which determine whether or not these organizations are actually collaborating. According to Fabricius Bank-Fund cooperation (or consistency) depends critically on the level of communication between the two organizations, where such exchange of information is not generally institutionalized but it has been let to the discretion of individuals (i.e., the staff members). ${ }^{12}$ Whether or not the Bank and the Fund cooperate has been found to depend on two conditions: similarity in the Bank's and the Fund's organizational structures (which facilitates communication), and the so called "domain consensus" (i.e., the degree to which they consent to the domain of their respective activities in the division of labor). ${ }^{13}$

\footnotetext{
${ }^{10}$ See, among others, Dessein (2002), Harris and Raviv (2005, 2008). For an empirical application of two-sided incomplete information - using the International Monetary Fund's structural programs - also see Marchesi et al. (2011).

${ }^{11}$ Some political scientists have focussed on the efficiency of the separation between the Fund and the Bank, arguing that these two institutions, while created for very different purposes, are nowadays indistinguishable and that their artificial separation is thus inefficient (e.g., Clark 1990; Crook 1991; Shultz 1998; Burnham 1999 and Fischer 2004).

${ }^{12}$ The main exception being the PRSPs which are prepared by the countries themselves together with the World Bank and the IMF. However, this only applies to low-income countries.

${ }^{13}$ An interesting implication emerging from this study is that Bank-Fund consistency may not always be desirable. According to Fabricious, pressures for conformity might jeopardize "ownership" of lending
} 
The third and final strand of literature we look at is empirical. Despite a vast literature considering the individual impact of the IMF and the WB on recipient countries' economic growth and development, little is known about the effects of the simultaneous presence of both institutions in a single country. Moreover, little empirical evidence exists about how and under what circumstances these two organizations work actually together. It is therefore difficult to distinguish the effect of their interaction from that of their simultaneous action, which may in itself have an effect. Marchesi and Sirtori (2011) have estimated the impact on economic growth of the joint participation in both IMF and WB programs. As a proxy of Bank-Fund interaction they used the simultaneous presence of a Bank and Fund program in the same country and at the same time. Using panel data for 128 developing countries over the 1982-2005 period, Marchesi and Sirtori find that the interaction between these two organizations has a positive and significant impact on growth. More specifically, the coefficient of IMF programs is negative and significant, the coefficient of World Bank programs is not significant while the coefficient of their interaction term is positive and significant at conventional levels. The results suggest that the WB can have a stronger impact on growth when the IMF is simultaneously involved as compared to when it is acting individually.

We contribute to this literature both theoretically and empirically. Regarding theory, we open the black box of Bank-Fund interaction by analyzing information transmission between them and identifying the main factors preventing full communication. To our knowledge, it is the first time that communication analysis is explicitly introduced in modelling Bank-Fund interaction. With respect to our empirical model, even though some papers have considered the impact of IMF (and WB) programs on growth individually, we are the first to test the impact of a "joint" IMF-WB loan and to investigate whether this impact is affected by the IMF and the WB willingness (or ability) to communicate.

\section{The model}

The theoretical framework is that of ADM and Rantakari (2008) appropriately modified to deal with the issues at hand. More specifically, differently from ADM, we assume that the Fund and the Bank (the two divisions in their context) are fully selfish. ${ }^{14}$ We believe that

conditions and thus he suggests that the Bank and the Fund should pursue a case-specific approach in deciding whether or not to coordinate. A similar problem is also addresses by Hagen (2010), who (theoretically) investigates how "ownership" could be affected by introducing more or less donor coordination.

${ }^{14}$ The selfishness of the two institutions might be explained by the circumstance that the career of both the Fund and the Bank staff members depend on skills and efforts which are exclusively related to the performance of each institution. 
this scenario better describes the existent situation in which the public evaluation of the two institutions exclusively responds to their own performance.

We start by deriving the equilibria in which the Fund and the Bank first learn their local conditions, then communicate with each other, and finally take their decisions (section 4.1 - 4.3). Equilibria will be partition equilibria, where each sender only indicates to which interval the realized state she observes belongs to, as in a standard cheap talk framework. We then compare, in section 4.4, the overall performance of this decentralized governance structure with the first best outcome (i.e., perfect symmetric information and centralized decision making). Finally, we show how the expected loss, relative to the first best, may vary considering the characteristics of the environment where the Fund and the Bank actually operate.

\subsection{Objective functions and decision making}

The trade off between coordination and adaptation can be formalized by assuming that the Fund and the Bank have to minimize the following quadratic loss functions, respectively

$$
\begin{gathered}
L^{F}=\left(d_{1}-\theta_{1}\right)^{2}+\delta_{1}\left(d_{1}-d_{2}\right)^{2} \\
L^{B}=\left(d_{2}-\theta_{2}\right)^{2}+\delta_{2}\left(d_{2}-d_{1}\right){ }^{2}
\end{gathered}
$$

where $d_{1}$ represents the Fund's decision, $d_{2}$, represent the Bank's decision and $\theta_{i} \in R$, $i \in\{1,2\}$, represents the specialized information of each institutions. The Fund observes its local conditions $\theta_{1}$ without knowing the Bank's local conditions (i.e., the realization of $\theta_{2}$ ) and vice-versa. It is common knowledge that $\theta_{1}$ and $\theta_{2}$ are uniformly distributed on $\left[-\bar{\theta}_{i}, \bar{\theta}_{i}\right]$, with $i=1,2$, and the draws of $\theta_{1}$ and $\theta_{2}$ are independent. The first term of the loss function represents the loss due to a not satisfactory adaptation to local conditions, that is $d_{i} \neq \theta_{i}$, while the second term represents the coordination loss that the Fund (and the Bank) incurs when their actions are not perfectly coordinated, that is $d_{1} \neq d_{2}$.

The parameter $\delta_{i} \in[0, \infty)$, for $i=1,2$, measures the relative weight that each institution gives to coordination losses relative to adaptation losses. In other words $\delta_{i}$ measures the dependency of institution $i$ from institution $j$. If there is a recognized supremacy of one institution over the other (at least for some area of intervention) we expect asymmetric dependency, with the "follower" highly dependent on the leading institution. If there is no recognized supremacy we expect symmetric dependency. The degree of the environmental volatility which the IMF faces is given by the variance of $\theta_{1}$ (i.e., $\sigma_{1}^{2}$ ), while that faced by the Bank is given by the variance of $\theta_{2}$ (i.e., $\sigma_{2}^{2}$ ). 
The IMF and the World Bank take their decisions under a decentralized governance structure. Namely, each institution takes decisions to minimize its own loss function, overlooking the effect which its own actions have on the other institution. Formally, the Fund and the Bank first observe their local conditions, then they send each other messages $m_{1}$ and $m_{2}$ about the realization of their own state of nature, and finally they take their decisions to minimize respectively $E\left[L^{F} \mid \theta_{1}, m_{2}\right]$ and $E\left[L^{B} \mid \theta_{2}, m_{1}\right]$. For analytical simplicity we now assume that $\delta_{1}=\delta_{2}=\delta$, while the case of asymmetric dependency will be discussed later. Taking the first order conditions of the expected value of (1) and (2) with respect to $d_{1}$ and $d_{2}$, we can derive the Fund and the Bank reaction functions. Then, solving the reaction functions for the equilibrium decisions yields

$$
d_{1}=a \theta_{1}+(1-a)\left(b E\left(\theta_{1} \mid \theta_{2}, m\right)+(1-b) E\left(\theta_{2} \mid \theta_{1}, m\right)\right)
$$

and

$$
d_{2}=a \theta_{2}+(1-a)\left(b E\left(\theta_{2} \mid \theta_{1}, m\right)+(1-b) E\left(\theta_{1} \mid \theta_{2}, m\right)\right),
$$

where $a=\frac{1}{1+\delta}$ and $b=\frac{\delta}{1+2 \delta}$.

The Fund decision is a convex combination of $\theta_{1}$, its posterior beliefs about $\theta_{2}$ (i.e., $E\left(\theta_{2} \mid\right.$ $\left.\theta_{1}, m_{2}\right)$ ), and the Bank posterior belief about $\theta_{1}$ (i.e., $\left.E\left(\theta_{1} \mid \theta_{2}, m_{1}\right)\right)$. Similarly, the Bank decision is a convex combination of $\theta_{2}$, its posterior beliefs about $\theta_{1}$, (i.e., $E\left(\theta_{1} \mid \theta_{2}, m_{1}\right)$ ), and the Fund posterior belief about $\theta_{2}$, (i.e., $\left.E\left(\theta_{2} \mid \theta_{1}, m_{2}\right)\right){ }^{15}$

\subsection{Strategic communication and communication equilibria}

Before taking actions, the Fund and the Bank communicate the realization of their observed state of nature by sending messages. However, the non-verifiability of information (i.e., soft information) creates communication problems. Indeed, there will be always an incentive for either the Fund or the Bank to exaggerate the realization of the state of nature, with a positive bias if $\theta_{i}>0$ and with a negative bias if $\theta_{i}<0$, with $i=1,2$. To give the intuition of the incentive to distort the transmitted information, let us now suppose that the Fund sends message $m_{1}$ to the Bank. From (4) it is easy to check that the Bank's expected response to message $m_{1}$ will be $(1-a)(1-b) E\left(\theta_{1} \mid \theta_{2}, m_{1}\right)$, with $(1-a)(1-b)<1$. Then, the Fund, anticipating the Bank's response, will try to induce a higher reaction by the Bank, by exaggerating the value of its report about the realized $\theta_{1} \cdot{ }^{16}$ Since rationality would lead the

\footnotetext{
${ }^{15}$ As $\delta \rightarrow \infty$, for given posterior beliefs, both decentralized decisions converge to the same value, that is $d_{1}=d_{2}=\frac{1}{2}\left[E\left(\theta_{1} \mid m_{1}\right)+E\left(\theta_{2} \mid m_{2}\right)\right]$. When $\delta=0$, the need to balance conflicting needs for adaptation disappears and both institutions will only put weight on the adaptation to their respective local conditions. This implies that $d_{1}=\theta_{1}$ and $d_{2}=\theta_{2}$.

${ }^{16}$ It is straightforward to show that only when $\theta_{1}=0$ communication will be truthful.
} 
Bank to "discount" the Fund's message, the IMF will be induced to exaggerate even further its reported value.

Nonetheless, in equilibrium, communication does not become meaningless as we might expect. Indeed, the incentive to lie is somewhat limited by the fact that the Fund not only wants the Bank to set an action close to its own, but also close to the true state of nature. When the incentive to lie is limited, CS show that imprecise cheap talk can indeed convey information. In the context of the coordination game we are analyzing, ADM obtain the same result: they show that all communication equilibria are interval equilibria in which the state space, $\left[-\bar{\theta}_{i}, \bar{\theta}_{i}\right], i=1,2$, is partitioned into intervals, and agent $i$ (for $i=1,2$ ) chooses a random message from the subinterval to which the true value $\theta_{i}$ belongs. ${ }^{17}$ The message, therefore, reveals to the other agent only the range in which the true observation lies and the quality of communication is indeed represented by the interval length: the coarser the partition, the nosier communication. It follows that the receiver's posterior on $\theta_{i}$, given the message $m_{i}$, is uniform on the interval that contains $m_{i}$ (i.e., $E\left(\theta_{i} \mid \theta_{j}, m_{i}\right)$ is the midpoint of the interval that contains $m_{i}$ ).

Let denote by $t_{i}^{2 N_{i}}=\left(t_{i,-N_{i}}, \ldots t_{i,-1}, t_{i, 0}, t_{i, 1}, \ldots t_{i, N_{i}}\right)$ the partitioning of $\left[-\bar{\theta}_{i}, \bar{\theta}_{i}\right]$, into $2 N_{i}$ intervals, for $i=1,2$ and $j=\left(-N_{i} \ldots 0,1 \ldots N_{i}\right)$. ADM show that in equilibrium the size of the generic interval $\left(t_{i, j+1}-t_{i, j}\right)$ is equal to the size of the preceding interval $\left(t_{i, j}-t_{i, j-1}\right)$ plus $4 \frac{1+\delta}{\delta} t_{i, j}$; symmetrically, the size of the interval $\left.\left(t_{i,-(j+1}\right)-t_{i,-j}\right)$ is equal to that of the preceding interval plus $4 \frac{1+\delta}{\delta} t_{i,-j}$. This implies that the quality of communication deteriorates as $\theta_{i}$ moves further away from its mean value, that is $\theta_{i}=0$. Therefore, the less information is communicated by each institution to the other, the larger the reported value of the state of nature is. This result is intuitive since the incentives to misrepresent information increase with the module of $\theta_{i}$. Furthermore, we can see that the length of the intervals decreases with $\delta$. Consistently with intuition, this means that communication becomes more precise as the need for coordination increases. ADM demonstrate that as the number of partitions $2 N_{i}$ goes to infinity, the most efficient Perfect Bayesian Equilibrium is achieved. ${ }^{18} \mathrm{In}$ such an equilibrium the size of the intervals is infinitesimally small for $\theta_{i}$ close to 0 and increases at a growing rate as the module of the observed $\theta_{i}$ increases. In what follows, we will refer to this equilibrium representing the focal point of the communication game.

Let $\bar{m}_{i}=E\left(\theta_{i} \mid \theta_{j}, m_{i}\right)$ denote the posterior expectation of the state $\theta_{i}$ by the receiver of message $m_{i}$. The variance of the posteriors is defined as $E_{\theta_{i}}\left(\bar{m}_{i}{ }^{2}\right)$, given that $E\left(\bar{m}_{i}\right)=0$. In

${ }^{17}$ The solution concept employed is Perfect Bayesian Nash equilibrium, which is simply a Nash equilibrium in which each agent responds optimally to his opponent's strategy choice, taking into account his probabilistic beliefs, and minimizing expected loss over his possible strategy choices.

${ }^{18}$ That is, $E\left[L^{F} \mid \theta_{1}, m_{2}\right]+E\left[L^{B} \mid \theta_{2}, m_{1}\right]$ is lower than in any other equilibria. 
the case of truthful communication (perfect information), $E_{\theta_{i}}\left(\bar{m}_{i}{ }^{2}\right)$ is equal to $\sigma_{i}^{2}$, while with meaningless communication (bubbling equilibrium), $E_{\theta_{i}}\left(\bar{m}_{i}{ }^{2}\right)$ is equal to zero. Therefore, we define as residual variance (or $R V$ ), the variance (or "volatility") related to the environment that institution $i$, ex ante, expects to face after receiving the message by the other institution. More formally

$$
R V=\sigma_{i}^{2}-E_{\theta_{i}}\left(\bar{m}_{i}^{2}\right) \text {, for } i=1,2 \text {. }
$$

The residual variance gives a measure of the information loss due to strategic communication. The coarser the space partition, the lower the value of $E_{\theta_{i}}\left(\bar{m}_{i}\right)$, and in turn the greater the information loss. In the focal equilibrium, ADM show that

$$
R V=S \sigma_{i}^{2}
$$

where

$$
S=\frac{\delta+1}{7 \delta+4}
$$

When the need of coordination need low, the quality of communication is in turn very low, and we can verify that $S$ tends to $\frac{1}{4}$ (upper bound) as $\delta$ goes to 0 . This means that as the coordination need tends to zero, agents reveal only the sign of the observed state of nature (that is the partition contains just two intervals). Conversely, the quality of communication improves as $\delta$ increases, but it always remains bounded away from perfect information: indeed, we can see that $S$ tends to $\frac{1}{7}$ (lower bound) as $\delta$ goes to infinity. Intuitively, although the two institutions agree on the need to better coordinate their actions, in a imperfect information context and with misaligned interests, each of them will distort the transmitted information in order to convince the other to make an adjustment that suits better its own preferences. In this way much valuable information is lost.

\subsection{Social expected loss}

Having derived the equilibrium decisions and the quality of communication in equilibrium, we can solve for the social expected loss. We define the social expected loss as the sum of the Fund and the Bank expected losses, that is

$$
E L^{\text {Social }}=E\left[\left(d_{1}-\theta_{1}\right)^{2}\right]+E\left[\left(d_{2}-\theta_{2}\right)^{2}\right]+2 \delta\left(E\left[\left(d_{1}-d_{2}\right)^{2}\right],\right.
$$

and by substituting (3) and (4) in (7) and taking (5) into account, we obtain 


$$
E L^{\text {Social }}=\frac{2 \delta}{(2 \delta+1)^{2}}(1+\delta)\left(\sigma_{1}^{2}+\sigma_{2}^{2}\right)+S\left(\delta^{2} \frac{2 \delta^{2}-1}{(\delta+1)^{2}(2 \delta+1)^{2}}+2 \delta^{2} \frac{2+3 \delta}{(1+\delta)^{2}(1+2 \delta)^{2}}\right)\left(\sigma_{1}^{2}+\sigma_{2}^{2}\right)
$$

Under decentralized governance - where the IMF and WB are privately informed and take decisions to minimize their own expected loss functions - there are two sources of inefficiency: one derives from the circumstance that each institution does not fully internalize the benefits of coordination, while the other depends on their strategic communication. We can therefore rewrite the social expected loss as being made by the two components $E L^{P I}$ and $E L^{C}$. The first component is obtained by putting $S=0$ in (8), that is

$$
E L^{P I}=\frac{2 \delta}{(2 \delta+1)^{2}}(1+\delta)\left(\sigma_{1}^{2}+\sigma_{2}^{2}\right)
$$

which shows the social expected loss under perfect information $(P I)$ and decentralized decision making. Therefore, (9) only captures the loss due to selfishness or own institution bias, which leads to choose "too distant" decisions relative to the first best.

The second component is the loss resulting from strategic communication $(C)$, that is

$$
E L^{C}=S\left(\delta^{2} \frac{2 \delta^{2}-1}{(\delta+1)^{2}(2 \delta+1)^{2}}+2 \delta^{2} \frac{2+3 \delta}{(1+\delta)^{2}(1+2 \delta)^{2}}\right)\left(\sigma_{1}^{2}+\sigma_{2}^{2}\right),
$$

where $S$ is given by (6). This loss captures the fact that coordination of actions is impaired by distorted information transmission.

\subsection{Expected performance of decentralized governance}

To better understand how the total expected loss may be affected by the actual characteristics of the environment in which the IMF and the WB operate, we will analyze the percentage increase in the expected loss, with respect to the first best outcome, depending on the two different sources of bias, namely $P I$ and $C$. We start by analyzing the first best outcome, that is the case in which there is perfect information and decisions are centralized. ${ }^{19}$ Assuming perfect information and centralized decision making, the expected loss function becomes the following

$$
E L^{F B}=E L^{F}+E L^{B}=E\left(d_{1}^{C}-\theta_{1}\right)^{2}+E\left(d_{1}^{C}-\theta_{2}\right)^{2}+2 \delta E\left(d_{1}^{C}-d_{2}^{C}\right)^{2} .
$$

\footnotetext{
${ }^{19}$ For example, we could think of an headquarter putting the "right" weight on the coordination losses.
} 
Taking the first order conditions of (11) with respect to $d_{1}^{C}$ and $d_{2}^{C}$, and solving for the equilibrium decisions, it is possible to show that

$$
d_{2}^{C}=(1-\gamma) \theta_{1}+\gamma \theta_{2}
$$

and

$$
d_{1}^{C}=\gamma \theta_{1}+(1-\gamma) \theta_{2}
$$

where

$$
\gamma=\frac{1+2 \delta}{1+4 \delta}
$$

Substituting (12) and (13) in (10) and taking the expected value we obtain

$$
E L^{F B}=\frac{2 \delta}{1+4 \delta}\left(\sigma_{1}^{2}+\sigma_{2}^{2}\right)
$$

The percentage increase in the expected social loss over the first best outcome is defined as

$$
\frac{E L^{\text {social }}-E L^{F B}}{E L^{F B}} .
$$

where equation (16) is obtained by summing the relative loss due to selfish decisions (or $S L$ ) and the relative loss due to strategic communication (or $C L$ ). More specifically, $S L$ is defined as the percentage increase in the expected loss over the first best outcome due to selfishness under decentralized decision making, that is

$$
S L=\frac{E L^{P I}-E L^{F B}}{E L^{F B}}
$$

while $C L$ is defined as the percentage increase in the expected social loss over the first best outcome when strategic communication is substituted for perfect information, that is

$$
C L=\frac{E L^{C}}{E L^{F B}}
$$

Proposition 1 and 2, both based on Rantakari (2008), show how both $S L$ and $C L$ are affected by $\delta$, that is the weight given to coordination losses as compared to adaptation losses.

Proposition 1 As the need of coordination increases, the quality of decentralized decisions initially worsens relative to the first best, then it gradually improves to eventually converge 
to the quality of centralized decisions, as $\delta$ goes to infinity.

\section{Proof. see Appendix A}

When the need of coordination is very low, decentralized decisions perform relatively well and $S L=0$, for $\delta=0$. The relative loss due to selfishness starts to increase, as $\delta$ increases, since the two institutions take decisions which are too distant relative to the first best outcome. However, as the need of coordination further increases, the quality of decentralized decisions starts improving to eventually converge to the quality of centralized decisions (i.e., $S L=0)$ as $\delta$ goes to infinity. Consistently with intuition, in a perfect information context, the inefficiency which is due to each institution own bias cancels out as the need to coordinate their decisions becomes the main concern of the two organizations.

Proposition 2 As the need of coordination increases, the relative expected loss due to strategic communication initially rises. As $\delta$ further increases, however, the quality of communication improves and the strategic communication loss eventually starts to decrease but it remains bounded away from zero since communication will never be perfect.

\section{Proof. see Appendix A}

Proposition 2 shows that when the need of coordination is very low, the relative expected loss is not relevant as communication is not so valuable. As the need of coordination increases, the expected loss due to strategic communication starts rising and a lot of valuable information is lost. However, as the need of coordination keeps on rising such loss starts decreasing since both the Fund and the Bank now assign more value to communication. As a result, communication becomes more reliable and less information will be lost, but truthful communication will never be achieved. Thus, $C L$ (unlike $S L$ ) remains bounded away from zero.

To sum up, as the need of coordination rises, $S L$ initially increases but starts eventually to decrease and goes to zero as $\delta$ goes to infinity. More intuitively, as the two institutions perceive a greater mutual dependency, they start to coordinate their actions in order to minimize their expected losses. Conversely, $C L$ remains bounded away from zero. Although the two institutions agree on the need of better coordinating their actions, in an imperfect information context (and with misaligned interests), communication is always distorted, since both actors will always try, by manipulating information, to induce the counterpart to make an adjustment closer to their own preferences. Therefore, when the need of coordination is relevant, as it is generally the case for the IMF and the WB given their strong complementarities, the primary source of inefficiency comes from strategic communication. 
In the next section we will investigate more carefully how the specific environment where both the Fund and the Bank operate may affect the specific component of the expected loss which is due to communication failure.

\subsubsection{Domain dissent vs. asymmetric dependency}

In order to focus on the specific determinants of coordination failure we need to emphasize two main aspects. On the one hand, if the recipient countries' specific conditions (which in turn may depend on their bureaucracy, ethnic divisions, geography and related aspects) allow both organizations to independently collect all the relevant information, there will be no strategic uncertainty. On the other hand, the more salient the share of private information (relative to common knowledge) in decision making is, the more important communication is, and thus the higher the costs of strategic uncertainty will be. In particular, Fabricious (2007) argues how Bank-Fund competition (i.e., their "domain dissent") may be one of the main factors jeopardizing communication. ${ }^{20}$ In other words Bank-Fund competition may leads both the Fund and the Bank to exaggerate the importance of their own staff members' opinions making them even more reluctant to accept others' inputs in taking decisions. Domain dissent therefore worsens both the selfishness and the strategic communication loss.

Moreover, as Fabricious (2007) also emphasized, domain dissent will be less likely when each organization's comparative advantage is clearer. For example, let consider a situation in which there is a recognized supremacy of one institution over the other (at least for some area of intervention). This can be defined as "asymmetric dependency." In this case the organization considered as the "follower" will place a higher weight on coordination losses than the organization considered as the "leader." In the extreme case in which, for example, the IMF recognizes the absolute supremacy of the WB on one area of intervention, (1) and (2) become

$$
L^{F}=\left(d_{1}-d_{2}\right)^{2}
$$

and

$$
L^{B}=\left(d_{2}-\theta_{2}\right)^{2}
$$

\footnotetext{
${ }^{20}$ Domain dissent denotes a situation in which the staff members of one organization do not approve the scope of the other organization's activities and it can even be motivated by pressures related to staff members' personal prestige. Such pressures, by reinforcing concerns for supremacy and differentiation, might jeopardize coordination over and above the failures due to decentralization and asymmetric information.
} 
With no competition, the Bank will truthfully reveal its observed state of nature $\theta_{2}$ to the IMF. Decentralized decisions will then always coincide with centralized decisions taken under perfect information and the first best will be achieved.

\subsection{Normative and empirical implications}

The main prediction of the theoretical model is that the social expected loss (relative to the first best) is made by two components: selfishness and strategic communication. In particular, two main factors are playing an important role in determining the relevance of the second type of loss: the level of competition (or domain dissent) between the two institutions and the relevance of their specific local information relative to the general expertise of multilateral organizations (or asymmetric dependency).

The model does provide some normative implications on how to ameliorate cooperation between IMF and WB. As for the selfishness bias we expect that the introduction of contract provisions directed to ameliorate incentive alignments between the two organizations would improve their overall performance. Specifically, in order to decrease the selfishness bias it is crucial that the staff members' are given the appropriate incentives aligned with the institutional commitments aimed at improving Bank-Fund collaboration. ${ }^{21}$ As for strategic communication, which is the most relevant bias when the need of coordination is high, the introduction of clear guidelines on information sharing between Bank and Fund staff would probably ameliorate (although not eliminate) the existing distortions. Furthermore, to remove the competition pressures that jeopardize cooperation over and above the distortions due to decentralized decisions, the two organizations should move towards a stronger division of labor. To this end, each organization's comparative advantage should be clearly restated in the changing context of policy based lending. ${ }^{22}$

Finally, the model contains also a clear testable implication. Since the overall performance of the two institutions is mainly impaired by strategic communication, we expect to find an empirical relationship between a measure of their joint performance and some variables measuring the degree of asymmetric information (asymmetric dependency) and/or the degree of competition between the two institutions (domain dissent). ${ }^{23}$ We turn to the empirics next.

\footnotetext{
${ }^{21}$ For example, the ability to work in team with the other organization's staff members could become a criterion to employ new people for both institutions. The proposal to introduce a recognition award for staff that demonstrate a particularly strong commitment to working constructively with their Bretton Woods counterparts is definitely going in this direction.

${ }^{22}$ See Fabricious (2007) for some proposals going in this direction.

${ }^{23}$ See Fabricious (2007) for more details on both aspects.
} 


\section{Empirical Model}

In this section we plan to analyze the joint effect of Bank-Fund intervention on recipient country's growth. More specifically, we take the impact of a loan which is granted simultaneously by the IMF and the WB on recipient country's growth as a measure of their joint performance. We want to test whether this impact is in turn influenced by some variables which we take as proxy of the IMF's and the WB's willingness (or ability) to communicate and coordinate.

We consider only the cases in which the IMF and the WB are lending simultaneously to a recipient country. We are well aware that being involved simultaneously with the same country does not necessarily mean that these two organizations are actually working together. The Bank and Fund could lend simultaneously to the same country without any exchange of information as well as exchanging information also at a distance. However, ceteris paribus, it is plausible to believe that these institutions will be more likely to interact when simultaneously "involved" with the same country as compared to the case in which they are acting on their own.

In this paper, we consider the amount of IMF and WB disbursements rather than taking the number of projects, as in Marchesi and Sirtori (2011). Since the effects of a loan can be evaluated only after a few years from the disbursement, all our variables are averaged over three years. We start by considering the impact on (a three year averaged) growth of the initial values of a joint IMF-WB loan (and its lagged value). We then evaluate the impact of the three year averaged IMF-WB loan (and its lagged value).

We use data only restricted to countries which have received a loan simultaneously by the IMF and the WB, that is a maximum of 90 developing countries over the period 19822008. ${ }^{24}$ We are aware that this choice could in principle be affected by a selection problem as countries that request a joint IMF-WB joint loan may, in principle, have some special characteristics that make them different from countries that apply to only one of the two institutions. However, to test for the robustness of our results, we also estimate an alternative specification using the full sample of countries. We then test

$$
G_{i t}=\alpha+\beta L_{i t}+\gamma X_{i t}+\delta L_{i t} * X_{i t}+\zeta Z_{i t}+\eta_{i}+\tau_{t}+u_{i t}
$$

where $G_{i t}$ represents per capita growth in country $i$ at period $t, L_{i t}$ denotes the sum of IMF and WB loans received by country $i$ at period $t, X$ is a vector containing our variables of

\footnotetext{
${ }^{24}$ In a similar setup Burnside and Dollar (2000) and Collier and Dollar (2001) use averages over four years, while Barro and Lee (2005) or Dreher (2006a) use five-year averages.
} 
interest, $L * X$ denote the effect that our variables of interest have on the simultaneous impact of an IMF-WB loan and $Z$ is a vector containing a set of control variables. Finally, $\eta_{i}$ and $\tau_{t}$ denote country and time dummies, respectively, which allow us to control for both countries unobservables and common macroeconomic factors.

We use a OLS fixed-effect estimator with robust standard errors in order to correct for heteroskedasticity across countries. When estimating the growth regression by OLS there may be the problem with the endogeneity of both the IMF and the WB variables as adjustment programs are usually concluded in periods of economic crisis and obviously selection problems may also be related to the interaction term between IMF and World Bank programs. Nevertheless we decided to use OLS to estimate both equation (21) and (??). The first reason is that we believe (as for example do Dreher et al. 2013 and Clemens et al. 2012) that OLS regressions are superior to 2SLS with questionable instruments. ${ }^{25}$ The second reason is that our estimate of whether IMF-WB loans affects growth is likely to be the lower bound of the true effect, moreover, we avoid to interpreting it in a causal way. However, we have no reason to expect a systematic bias for the interaction terms with our variables of interest.

\section{Data}

\subsection{Control Variables}

Our choice of control variables follows the specification of Marchesi and Sirtori (2011), which, in turn, followed a common specification in the literature analyzing the effects of both IMF and WB programs (and foreign aid). ${ }^{26}$ Our selection then includes economic, institutional, and social variables. More specifically, we control for the log of GDP per capita at the start of each period, measures for human resources (life expectancy and fertility rate), investment as a percentage of GDP, a measure of openness (exports and imports over GDP), an index of democracy as defined in the Polity IV dataset (ranging from -10 to 10) and the CPIA index of the World Bank which measures the quality of policies and institutions (reflecting the Bank's internal evaluation of country performance and institutions). ${ }^{27}$

\footnotetext{
${ }^{25}$ Dreher et al. (2013a) and (2013b) and Kilby (2012) have all recently shown how that politically driven aid (and WB projects) have negative outcomes. For this reason political variables cannot be (anymore) valid instruments in aid (and loans) effectiveness regressions.

${ }^{26}$ Among others, see Barro and Lee (2005), Dreher (2006a) and Rajan and Subramanian (2008).

${ }^{27}$ We also tried to include some measures for "education" and some of the ICRG indicators but missing data reduced the sample substantially, so we do not report the results below. We have also included the KOF Index of Globalization and its subcomponent on economic restrictions (Dreher, 2006b) and our results are unchanged. Different specifications are available upon request.
} 


\subsection{Variables of interest}

Our variables of interest should include the factors that may affect the quality of communication between the two organizations. This set of variables is made of four main types of indicators. First of all, we include variables which are meant to capture the salience of their private information (i.e., the importance of the local vs. the multilateral's specific information. Then, following Fabricius (2007), we consider the role of the domain dissent in explaining Bank-Fund cooperation. ${ }^{28}$ Finally, we control for the possible role of political factors in inducing more or less cooperation between the two institutions.

Importance of the local knowledge. The quality and the extent of communication is jeopardized by the relative weight given to adaptation to local conditions as revealed by each institution specialized information. However, if local knowledge is easily accessible and no specialized expertise is needed to acquire it, distorted communication does not represent a problem anymore. To this respect, we use the quality of information transmission as a proxy of the salience of the private information between the two organizations. With a higher quality of information transmission it is easier to verify information and, therefore, to assess its relevance and importance for decisions and outcomes. As a consequence, as information asymmetry decreases, the cooperation between the Bank and the Fund should improve. We use the number of telephone lines per 100 inhabitants (World Telecommunications/ ICT Indicators Database 2011) as a proxy for the quality of information transmission. ${ }^{29}$ Higher values indicate higher quality, and thus less importance of differences in knowledge endowment. $^{30}$

Importance of the multilateral general expertise. The greater the importance of the multilateral's general knowledge (with respect to local knowledge) in designing adjustment programs, the less important the bias due to strategic communication and therefore we expect a stronger

\footnotetext{
${ }^{28}$ Fabricious (2007) empirically shows that whenever the Bank and the Fund agree on the boundaries of each other's operations (the so called domain consensus), they tend to speak with one voice. However, the increasing overlap of the mandates of the two organizations over time has amplified the areas of potential conflict, since each institutions tends to exaggerate the importance of their own opinions overlooking the importance of compromise.

${ }^{29}$ For more recent years, the availability of internet access might be a better proxy, but the use of this variable would substantially restrict our sample. The number of telephone lines correlates highly with this and other potential measures for the intensity of communication.

${ }^{30}$ Following Marchesi et al. (2011) we have also considered a alternative measures for the importance of the country's information, namely press freedom and a transparency indicator showing the share of series for which there are no data available in a given country and year (out of the 250 series classified as "economics" in the World Bank's World Development Indicators, 2008). However, while neither these variables nor their interactions are significant at conventional levels, the results for the remaining variables are unchanged. Instead of information transmission we obtain similar results by including an index of "Social Globalization," which considers personal contact, information flows and cultural proximity (http://globalization.kof.ethz.ch/).
} 
impact on growth of the Bank-Fund simultaneous involvement in a recipient country. ${ }^{31}$ In particular, the IMF and the WB's informational advantage will be more relevant for more open countries since multilateral institutions could be an ideal place to internalize spillovers (Rajan, 2008). We employ the indicators of openness to test this hypothesis. ${ }^{32}$

Competition or domain dissent. We measure the potential for domain dissent considering the "scope" of IMF conditionality, namely the number of areas covered by an IMF program. Greater scope means greater room for overlap (i.e., the IMF is more likely to interfere with the WB's actions) which in principle would imply greater potential disagreement as to "who gets what for what purpose." Such disagreement might trigger two different responses: either expressing disagreement (voice) or withholding information (exit) (Hirshman, 1970). If "channels of negotiation" remain open, disagreement does not necessarily lead to distorted communication and lack of cooperation. Shortfall in cooperation is rather observed in a situation in which withholding of information would be perceived more effective than negotiating in order to claim leadership on given areas. Therefore, ex ante, it is not easy to define the expected outcome of an increase in the "scope" of IMF conditionality. According to Fabricious (2007), disagreements are more likely to be observed in macroeconomic policy, fiscal policy, and financial sector reform, while other policy areas (i.e., privatization, agricultural policy, trade policy, and aid coordination) would show a substantial domain consensus. As a consequence, contrary to intuition, it could happen that increasing the scope of IMF conditionality actually improves the probability of letting channels of communication open between the two institutions, as there is more room for identifying different area of specialized competence.

To capture the scope of IMF conditionality we follow Marchesi et al. (2011) and build 20 categories, allocating all conditions to one of them, with the 20th category containing the residual. These categories refer to: Arrears, Balance of Payments/Reserves, the Capital Account, Central Bank Reform, Credit to Government, Debt, Exchange system, Financial sector, Governance, Government Budget, Monetary Ceiling, Pricing, Private Sector Reforms, Privatization, Public Sector, Social, Systemic, Trade and Wages \& Pensions. Clearly, these categories are to some extent arbitrary and some of them represent sub-categories of others. ${ }^{33}$

\footnotetext{
${ }^{31}$ The informational advantage of a multilateral institution derives from cross-country knowledge it accumulates during its activities. See on this point Marchesi et al. (2011).

${ }^{32}$ Instead of openness to trade, similat results are obtained including, the KOF Index of Globalization and its subcomponent on economic restrictions (http://globalization.kof.ethz.ch/) (Dreher,

${ }^{33}$ We focus on the scope of IMF conditionality, while ignoring the WB conditions, as in our sample, WB programs are much more common than IMF programs. Thus, what makes the difference in most cases is the (additional) intervention of the IMF. We find similar results controlling for the number of conditions in IMF programs.
} 
Political factors. The role of political factors in explaining the preferential treatment to allies of major shareholders of International Financial Institutions (IFI) is well known. ${ }^{34}$ In our analysis we are interested to test how political aspects may affect Bank-Fund cooperation. On the one hand, if political interferences are "symmetric," it is reasonable to expect that they make the two institutions more willing to find an agreement. On the other hand, asymmetric political pressure could jeopardize the cooperation between the IMF and the WB. We control for whether a country votes (more or less) in line with the United States in the United Nations General Assembly (UNGA) (or with other "key" shareholders of the IMF and the WB) as proxy of the importance that political factors may have for both IMF and WB intervention, and we interact this variable with a loan granted simultaneously by the IMF and the WB. ${ }^{35}$

We also emphasize that politically motivated aid (and WB projects) have recently been shown to have a negative outcome per se (see Dreher et al. 2013a; Dreher et al. 2013b and Kilby 2013) and we expect a similar results for Bank-Fund's loans. Therefore, in the simple analysis of the interaction term we are not actually able to disentangle the effects due to the Bank-Fund interaction from the effects of politically driven loans.

Appendix B presents the list of countries while Appendix C contains details of the definitions and sources of the variables included in the regressions. Finally the descriptive statistics are provided in Appendix D.

\section{Empirical results}

This section presents the regression results of the "restricted" specification in equation (21) where we take the initial value of a simultaneous loan by the IMF and the WB. The results are presented in Table 1 . Column 1 reports the coefficients of the variables that are most commonly used in the literature analyzing the effects of both IMF and WB programs (and foreign aid). Column 2 shows include our variables of interest as well as the control variables, while column 3 contains only our variables of interest and their interactions with the (initial values) of the joint IMF-WB loan them. Finally column 4 includes all variables.

\footnotetext{
${ }^{34}$ There is substantial empirical evidence linking a country's geopolitical proximity to the Fund's major shareholders with a variety of types of preferential treatment (e.g., Thacker 1999; Barro and Lee 2005; Dreher and Jensen 2007; Dreher et al. 2008a; Dreher et al. 2008b, Stone 2008; Moser and Sturm 2011). The influence of political aspects on the World Bank has been less investigated, still there is some evidence documenting their impact in programs' participation and credit allocation (e.g., Dreher, Sturm and Vreeland 2009; Kaja and Werker 2010; Kilby 2009).

${ }^{35}$ Dreher et al. (2009a) and (2009b) find evidence of a preferential treatment by both the IMF and the WB (respectively) for countries serving on the United Nations Security Council (UNSC). More recently, Dreher et al. (2013b) show that the effect of aid on economic growth is reduced by the share of years a country has served on the UNSC in the period the aid has been committed.
} 
Overall, the regressions in column 1 focus on the main variables that have been shown to influence growth in the existing empirical literature. First of all we do detect a positive effect on growth of a joint Bank-Fund loan. The disbursement of a simultaneous IMF-WB loan is significant at the one percent level: its increase by one standard deviation increases per capita growth by almost 0.6 percent. Most explanatory variables have the expected impact on growth: growth rates significantly increases with lower initial GDP, higher investments, and higher scores of the CPIA index, as expected. The coefficients of life fertility, life expectancy and democracy are not significant.

Column 2 turns to our variables of interest. As can be seen, none of them is significant in this specification, while the other explanatory variables maintain similar signs and significance levels as in column 1 (with the exception of life expectancy which now becomes significant at the five percent level and with the expected sign).

Column 3 includes the our variables of interest and their interactions with the initial values of a joint IMF-WB loan, while column 4 include them all. Since the results of column 3 and 4 are very similar, we focus on those of the most complete specification in column 4 . As before we detect a positive effect on growth of a joint Bank-Fund loan. The disbursement of a simultaneous IMF-WB loan is significant at the ten percent level and substantively important: its increase by one standard deviation increases per capita growth by almost two percent. The finding of a positive coefficient is reassuring with respect to the (plausible) consequences of the endogeneity of an IMF and WB program adoption as in this case a downward bias in the estimate of such coefficient is expected.

As far as our variables of interest are concerned, we observe that the coefficient of the interaction between a joint IMF and WB loan with the variable information transmission is positive but marginally insignificant ( $\mathrm{p}$-value is 0.105 ). However, in order to look at the specific effect (on growth) of the IMF-WB loan at different levels of information transmission, we calculated the marginal effects of the interaction (as displayed in Figure 1).

The results show that the critical amount of info transmission above which the marginal effect of Bank-Fund loans on growth is positive and significant is about 2.5, which is actually below the sample average value of five. Therefore, the impact of a joint loan on growth is not significant only for very low values (below 2.5) of info transmission and positive and increasing with information transmission thereafter. This evidence seems to suggest that the more easily the two institutions can gather country-specific information, the more beneficial their joint intervention in a country can become, which is consistent with the theory.

The coefficient of the interaction with openness is positive and significant at the five percent level of significance, suggesting that the positive impact of growth of simultaneous Bank- 
Fund loans increases the more open a country is, that is the more important the BankFund's general knowledge is with respect with the "local information." When we graph the marginal effect of Bank-Fund simultaneous intervention for different levels of openness, the results show that the critical amount of openness above which the marginal effect of BankFund loans on growth is positive and significant is about thirty, which is definitely below the sample average value of about seventy. Therefore, we can conclude that the impact of a joint loan on growth is always positive and increasing with the importance of the multilaterals' general information, which is consistent with the theory.

The coefficient of the interaction with scope is positive and significant at the five percent level of significance, suggesting that the positive impact of growth of joint Bank Fund loans increases the broader the IMF's conditionality is. When we graph the marginal effect of Bank-Fund simultaneous loans for different levels of scope, the results show that the critical amount of scope above which the marginal effect of Bank-Fund loans on growth is positive and significant is about 0.7 , which is below the sample average value of about 1.7 . Thus, the impact of a joint loan on growth is always positive and increasing with the number of areas covered by an IMF program. This result may seem at odds with intuition, however, as discussed by Fabricious (2007), it is plausible to believe that communication between the two institutions becomes easier when there are more intervention areas (i.e., greater scope) as compared to the case in which those areas are restricted to the three many policy areas where domain dissent is concentrated.

The interaction with voting in line with the US in the UNGA is negative and significant at the five percent level meaning that the effect of Bank-Fund loans on growth is significantly lower when such loans have been disbursed for political reasons. This result is consistent both with previous results of the related literature showing the negative effects of politically motivated aid (Dreher et al. 2013) and also with the possible adverse consequences of politically motivated loan disbursements on the Bank-Fund willingness to cooperate. ${ }^{36}$ The next section provides some robustness checks.

\section{TABLE 1 HERE}

\section{FIGURE 1-4 HERE}

\footnotetext{
${ }^{36}$ We obtain similar results focusing only on key votes. Finally, we have also included the interaction of a joint Fund-Bank's loan with the dummy for temporary UNSC membership. While neither the dummy nor the interaction are significant at conventional levels, the results for the remaining variables are unchanged.
} 


\section{Robustness checks}

This section presents a number of robustness checks. We start by showing the regression results of the "restricted" specification in equation (21) where we take the three-year averages instead of the initial value of the joint IMF-WB loan. While table 2 shows the contemporaneous average values, table 3 presents the results obtained lagging the average values and their interactions. Columns 1-4 of Table 2 follow the same specifications described in Table 1 and the results are very similar to those. We focus here only on the results of the most complete specification displayed in column 4

The disbursement of a simultaneous IMF-WB loan is still positive and now significant at the one percent level. As far as our variables of interest are concerned, we observe that the coefficient of the interaction between a joint IMF and WB loan with the variable information transmission is positive and not significant. However, when we calculated the marginal effects of this interaction (as displayed in Figure 5) the results show that they are positive at each level of info transmission. As before, the coefficient of the interaction with openness is positive and significant at the one percent level, suggesting that the positive impact of growth of simultaneous Bank-Fund loans increases the more open a country is, which is confirmed by the marginal effect of Bank-Fund simultaneous intervention for different levels of openness (as presented in Figure 6).

As before, the coefficient of the interaction with scope is positive and significant at the five percent level and the marginal effect of Bank-Fund simultaneous loans for different levels of scope, confirm such positive effect. The interaction with voting in line with the US in the UNGA is negative and now significant at the one percent level meaning that the effect of Bank-Fund loans on growth is significantly lower when such loans have been disbursed for political reasons, evidence which is confirmed by the marginal effects presented in Figure 8.

\section{TABLE 2 HERE}

\section{FIGURE 5-8 HERE}

Table 3 presents the results obtained by lagging the average values and their interactions. The results of this specification are actually weaker than those described earlier. The effect on growth of the disbursement of a simultaneous IMF-WB loan per se is no longer significant. However, that coefficient of its interaction with the variable information transmission is now positive and significant at the one percent level of significance, evidence which is confirmed by the marginal effects, as displayed in Figure 9. To the contrary, the coefficients of the others interactions, nor their marginal effects, are not significant.

TABLE 3 HERE 


\section{FIGURE 9 HERE}

Finally, to test for the robustness of our results, we also estimate an alternative specification using the full sample of countries, that is a maximum of 128 developing countries over the 1982-2008 period. The main advantage of this specification is that it allows us to distinguish between the impact of the money disbursed and the impact of simple participation. Specifically, we test the following equation

$$
\begin{aligned}
G_{i t}= & \alpha_{1}+\beta_{1} L_{i t}+\gamma_{1} X_{i t}+\delta_{1} L_{i t} * X_{i t}+\vartheta d I W+\lambda d I W * L_{i t}+ \\
& \mu d I W * X_{i t}+\nu d I W * L_{i t} * X_{i t}+\zeta_{1} Z_{i t}+\rho_{i}+\tau_{t}+\varepsilon_{i t}
\end{aligned}
$$

where $L_{i t}$ denotes the sum of IMF and WB loans received by country $i$ at period $t, d I W$ is a dummy variable which is equal to one when a country receive a loan simultaneously by the IMF and the WB, $d I W * L$ denotes the impact on growth of an IMF-WB loan and $d I W$ $* L * X$ denotes the effect that our variables of interest have on the simultaneous impact of an IMF-WB loan. ${ }^{37}$ As above, $X$ is a vector containing our variables of interest, $Z$ is a vector containing a set of control variables and $\rho_{i}$ and $\tau_{t}$ denote country and time dummies, respectively.

Table 4 presents the results of the "full" specification in equation (??). As above we focus on the results of the most complete specification presented in column 4 . We can observe that while the effects on growth of the (initial value of) adoption of either an IMF or a WB loan has a negative impact on growth (as well as the dummy indicating simple participation), the coefficient of the variable denoting their simultaneous presence is positive and larger than the first one, which is consistent with our previous results. We also find similar results both considering the variables of interest and the explanatory variables. As the variables of interest are concerned, the main difference is related to the sign of the interaction of the Bank-Fund loan with information transmission, which is now significantly negative rather than positive. ${ }^{38}$ The coefficients of the others interactions, nor their marginal affects, are not significant at conventional levels. ${ }^{39}$

\section{TABLE 4 HERE}

In summary, the empirical analysis confirms that Bank-Fund joint intervention is beneficial to growth (as in Marchesi and Sirtori, 2011) and that such beneficial effect is increasing with

\footnotetext{
${ }^{37}$ Since $X * L * d I W$ is a triple interaction we need to control for each possible combination of these three variables.

${ }^{38}$ However, calculating the marginal effects of this interaction we find that is not significant for "reasonable" values of the variable info transmission.

${ }^{39}$ Marginal effects are available upon request.
} 
the availability of the country's specific information (which decreases the asymmetry of information between the two institutions), with the importance of the multilaterals' knowledge (which decreases the relevance of local knowledge) and with the scope of IMF's conditionality (which makes communication easier for the two institutions by decreasing their competition). The next section provides policy implications and concludes.

\section{Conclusions}

Despite a series of official agreements aimed at strengthening Bank-Fund cooperation, it is widely believed that coordination between the two organizations often falls short of what should be rationally expected. In this paper we present a theoretical model which, focusing on the quality of information transmission between the IMF and the WB, analyzes the sources of the expected loss in the overall performance of the two institutions relative to the first best outcome, defined as a situation where decisions are centralized and information is perfect. When the need of coordination is relevant, as it is generally the case for the IMF and the WB, theoretical results show that the main source of loss is strategic communication. In turn, the bias which is due to strategic communication is indeed increased by the level of competition between the two institutions (or domain dissent), which makes each of them overlook the need of compromise, and by a greater importance of the local conditions, as revealed by each institution specialized expertise in policy design.

A testable implication of the model is then to relate Bank-Fund performance to their willingness (or ability) to communicate. As a measure of their performance we take the impact of a Bank-Fund simultaneous loan on recipient country's growth and, consistently with the theoretical results, we find that such beneficial effect negatively depends on variables related to the importance of Bank-Fund competition and to the salience of their private information. More specifically, the beneficial effect is increasing with the availability of the country's specific information (which decreases the asymmetry of information between the two institutions), with the importance of the multilaterals' knowledge (which decreases the relevance of the local knowledge) and with the scope of IMF's conditionality (which decreases the level of competition making communication easier for the two institutions).

This paper contains a number of policy implications. More generally, it provides a theoretical foundation to a large number of official reports encouraging more information sharing between the two institutions. Then, the theoretical model provides more specific policy indications on how to ameliorate cooperation between IMF and WB. As the first component

of the expected loss is concerned (or selfishness) we expect that the introduction of contract provisions directed to ameliorate incentive alignments between the two organizations would 
improve their overall performance. As for strategic communication, the introduction of clear guidelines on information sharing between Bank and Fund staff would probably ameliorate (although not eliminate) the existing distortions. Furthermore, a stronger division of labor would help to remove competition problems.

The paper could be extended in at least a couple of directions. First of all, we could extend our model analyzing what happens when the assumption of fully selfish institutions is (at least slightly) relaxed (as it is in ADM). More specifically, we expect to find that the introduction of some incentive alignments between the two organizations would ameliorate the performance of a decentralized governance. Finally, our analysis could be extended to consider the interaction of other types of international organizations and even to donors' coordination. In particular, it is now widely recognized that foreign aid in the typical developing country is highly fragmented and the so-called "new rhetoric on aid" clearly identifies aid fragmentation, and the related coordination failure, as one of the main problems in aid allocation (e.g., see the Paris Declaration on Aid Effectiveness, OECD 2005). ${ }^{40}$ We leave both questions for future research.

\section{References}

[1] Alonso R., Dessein D. W., and N. Matouschek (2008) "When does Coordination Require Centralization?" American Economic Review, 98, 145-179.

[2] Barro R.J. and J.W Lee (2005) "IMF Programs: who is chosen and what are the effects?" Journal of Monetary Economics, 52, 1245-1269.

[3] Birdsall N., and D. Kapur (2005) "The Hardest Job in the World: Five Crucial Tasks for the New President of the World Bank." Washington: Center for Global Development.

[4] Boughton J. (2001) "Silent Revolution: The International Monetary Fund, 19791989." Washington: International Monetary Fund.

[5] Burnham J.B. (1999) "The IMF and World Bank: time to merge." The Washington Quarterly, 22, 101-111.

[6] Burnside C., and D. Dollar (2000) "Aid, Policies and Growth." American Economic Review 90, 847-868.

\footnotetext{
${ }^{40}$ Öhler (2012), for example, finds evidence of a limited coordination effort across regions and sectors among bilateral donors within a recipient country (Cambodia).
} 
[7] Collier P. and D. Dollar (2002). "Aid allocation and poverty reduction." European Economic Review 46, 1475-1500.

[8] Clark L. H. (1990). "Let's Merge the World Bank and the IMF.". Wall Street Journal, 4 January.

[9] Clemens, C., Radelet S., Bhavnani R., and S. Bazzi (2012) "Counting chickens when they hatch: Timing and the Effects of Aid on Growth." Economic Journal 122, 561: 590-617.

[10] Crook C. (1991). "Sisters in the Wood - A Survey of the IMF and the World Bank.". The Economist, 12 October.

[11] Crawford V., and J.Sobel. (1982) "Strategic Information Transmission." Econometrica, $50,1431-1451$.

[12] Dixit A. (2009) "Governance, Institutions and Economic Activity." American Economic Review 99, pp. 5-24.

[13] Dreher A. (2006a), "IMF and economic growth: the effects of programs, loans and compliance with conditionality." World Development, 34, 769-788.

[14] Dreher A. (2006b) "Does Globalization Affect Growth? Evidence from a new Index of Globalization." Applied Economics, 38, 1091-1110.

[15] Dreher A. and N.M. Jensen (2007) "Independent Actor or Agent? An Empirical Analysis of the Impact of U.S. Interests on IMF Condition." Journal of Law and Economics, $50,105-124$.

[16] Dreher A., Sturm J-E, and J.R Vreeland (2009a) "Global Horse Trading: IMF loans for votes in the United Nations Security Council." European Economic Review, 53, 742-757.

[17] Dreher A., Sturm J-E, and J.R Vreeland (2009b) "Development Aid and International Politics: Does membership on the UN Security Council influence World Bank decisions?" Journal of Development Economics, 88, 1-18.

[18] Dreher A., Klasen S., Vreeland J.R. and E. Werker, (2013a) The costs of favoritism: Is politically-driven aid less effective? Economic Development and Cultural Change, forthcoming.

[19] Dreher A. Eichenauer, V and K. Gehring (2013b) "Geopolitics, Aid, and Growth", CESifo Working Paper No. 4299. 
[20] Easterly W. (2006) "The White Man's Burden: Why the West's Efforts to Aid the Rest Have Done So Much Ill and So Little Good." London: The Penguin Press.

[21] Easterly W. (2008) "Institutions: Top Down or Bottom Up?", American Economic Review, Papers and Proceedings, 98, 95-99.

[22] Fabricius M. (2007) "Merry Sisterhood or Guarded Watchfulness? Cooperation Between the International Monetary Fund and the World Bank." WP 07 - 9 Peterson Institute for International Economics.

[23] Fischer F. (2004) "Thinking the Unthinkable: Combining the IMF and World Bank" The International Economy Fall.

[24] Feinberg R. (1988) "The changing relationship between the World Bank and the International Monetary Fund." International Organizations, 42, n.3 :545-56.

[25] Gold J. (1982) "The relationship between the International Monetary Fund and the World Bank." Creighton Law Review, 15: 499 -521.

[26] Hagen R. (2010) "Dancing the H-Street Waltz? Policy Choice in Aid-Dependent Countries." Mimeo.

[27] Hirschman A. O. (1970) "Exit, Voice, and Loyalty: Responses to Decline in Firms, Organizations, and States." Harvard University Press.

[28] IMF (1998). External Evaluation of Enhanced Structural Adjustment Facility (ESAF): Report by a Group of Independent Experts.

[29] Kaja A. and E. Werker (2010) "Corporate Misgovernance at the World Bank and the Dilemma of Global Governance." World Bank Economic Review, 24, 171-198.

[30] Kilby C. (2009) "The political economy of conditionality: An empirical analysis of World Bank loan disbursements." Journal of Development Economics, 89, 1, 51-61.

[31] Kilby, C. (2013) "The political economy of project preparation: An empirical analysis of World Bank projects." Journal of Development Economics, 105: 211-225

[32] Krueger A. (1997) "Wither the World Bank and the IMF?" NBER Working Paper 6327.

[33] IMF and World Bank (2001) Strengthening IMF-World Bank Collaboration on Country Programs and Conditionality (August). 
[34] IMF and World Bank (2007) Final Report of the external review committee on BankFund collaboration (February).

[35] IMF (2007) Malan Report .Report Of The External Review Committee On Bank-Fund Collaboration. Available online: www.imf.org/external/np/pp/eng/2007/2022307.pdf

[36] IMF (2010) Implementation of the Joint Management Action Plan on Bank-Fund Collaboration. Available on line: www.imf.org/external/np/pp/eng/2010/030310.pdf

[37] Mallaby S. (2004) "The World's Banker: A Story of Failed States, Financial Crises, and the Wealth and Poverty of Nations." Council on Foreign Relations Books, Penguin Press.

[38] Marchesi S., Sabani L. and A. Dreher (2011), "Read my lips: the role of information transmission in multilateral reform design." Journal of International Economics, 2011, 84, pp. 86-98.

[39] Marchesi S, and E. Sirtori (2011) "Is two better than one? Effects on growth of BankFund interaction." Review of International Organization, 2011, 6, pp 287-306.

[40] Marshall M.G. and K. Jaggers (2009) "Polity IV Project: Political Regime Characteristics and Transitions, 1800-2007." University of Maryland.

[41] Moser, C. and J.-E. Sturm (2011): "Explaining IMF Lending Decisions after the Cold War." The Review of International Organizations, 6(3), 307-340.

[42] OECD (2005) The Paris Declaration on Aid Effectiveness and the Accra Agenda for Action. Available from: www.oecd.org/dataoecd/11/41/34428351.pdf.

[43] Öhler, H. (2012) "Do Aid Donors Coordinate Within Recipient Countries?", mimeo

[44] PRS Group (1998) "International Country Risk Guide (ICRG)" 19, 4. Syracuse, NY: IBC. http://www.prsgroup.com

[45] Rantakari H. (2008) "Governing Adaptation." Review of Economic Studies, 75, 12571285.

[46] Rajan R. (2008) "The future of the IMF and the World Bank." American Economic Review, Papers and Proceedings, 98, 110-115.

[47] Rajan R., and A. Subramanian (2008) "Aid and growth: what does the evidence really show." The Review of Economics and Statistics, 90(4): 643-665. 
[48] Shultz, G. P. (1998). "Merge the IMF and World Bank". The International Economy. January/February: 14-16.

[49] Stone R. (2008) "The Scope of IMF Conditionality: How Autonomous is the Fund?" International Organization, 62, 589-620.

[50] Thacker S. (1999) "The High Politics of IMF Lending." World Politics, 52, 38-75.

[51] The Economist "The UN and the World Bank: Rare co-operation." Jun 1st 2013.

[52] Voeten E. (2004) "Documenting Votes in the UN General Assembly." http://home.gwu.edu/ voeten/UNVoting.htm

[53] Woods N. (2006) "The Globalizers. The IMF, the World Bank, and their Borrowers." Cornell University Press.

[54] World Bank (2008), World Development Indicators, CD-Rom. Washington, D.C.

[55] Truman E.M. (2006) "A Strategy for IMF Reform." Policy Analyses in International Economics 77 Washington: Institute for International Economics. 
Table 1: Growth in the restricted sample (initial values), 1982-2008, OLS

\begin{tabular}{|c|c|c|c|c|}
\hline & (1) & $(2)$ & (3) & (4) \\
\hline Initial IMF \& WB loans & $\begin{array}{c}0.930^{* * *} \\
(2.680)\end{array}$ & $\begin{array}{c}1.052^{* * *} \\
(3.353)\end{array}$ & $\begin{array}{l}3.454^{* *} \\
(2.419)\end{array}$ & $\begin{array}{l}2.971^{*} \\
(1.887)\end{array}$ \\
\hline Information transmission & & $\begin{array}{c}0.107 \\
(1.190)\end{array}$ & $\begin{array}{c}-0.028 \\
(-0.323)\end{array}$ & $\begin{array}{c}0.044 \\
(0.442)\end{array}$ \\
\hline Openness & & $\begin{array}{c}0.009 \\
(0.812)\end{array}$ & $\begin{array}{c}0.020 \\
(1.520)\end{array}$ & $\begin{array}{c}0.003 \\
(0.260)\end{array}$ \\
\hline Scope & & $\begin{array}{c}-0.043 \\
(-0.511)\end{array}$ & $\begin{array}{l}-0.270^{* *} \\
(-2.187)\end{array}$ & $\begin{array}{l}-0.328^{* *} \\
(-2.534)\end{array}$ \\
\hline UNGA voting & & $\begin{array}{c}-0.950 \\
(-0.158)\end{array}$ & $\begin{array}{c}6.935 \\
(1.018)\end{array}$ & $\begin{array}{c}6.442 \\
(0.843)\end{array}$ \\
\hline Initial per cap. GDP (log) & $\begin{array}{c}-2.286 \\
(-1.454)\end{array}$ & $\begin{array}{c}-4.838^{* * *} \\
(-4.109)\end{array}$ & & $\begin{array}{c}-4.735^{* * *} \\
(-4.189)\end{array}$ \\
\hline Investment & $\begin{array}{c}0.129^{* * *} \\
(4.465)\end{array}$ & $\begin{array}{c}0.156^{* * * *} \\
(4.976)\end{array}$ & & $\begin{array}{c}0.148^{* * *} \\
(4.675)\end{array}$ \\
\hline CPIA & $\begin{array}{c}1.922^{* * *} \\
(5.975)\end{array}$ & $\begin{array}{c}1.895^{* * *} \\
(5.564)\end{array}$ & & $\begin{array}{l}1.976^{* * *} \\
(5.912)\end{array}$ \\
\hline Life expectancy $(\log )$ & $\begin{array}{c}-2.937 \\
(-1.356)\end{array}$ & $\begin{array}{l}-4.951^{* *} \\
(-2.514)\end{array}$ & & $\begin{array}{l}-5.242^{* *} \\
(-2.582)\end{array}$ \\
\hline Life fertility $(\log )$ & $\begin{array}{c}-1.067 \\
(-0.299)\end{array}$ & $\begin{array}{c}0.987 \\
(0.244)\end{array}$ & & $\begin{array}{c}1.842 \\
(0.457)\end{array}$ \\
\hline Democracy & $\begin{array}{c}0.004 \\
(0.103)\end{array}$ & $\begin{array}{c}0.013 \\
(0.346)\end{array}$ & & $\begin{array}{c}-0.000 \\
(-0.012)\end{array}$ \\
\hline Initial IMF \& WB loans $x$ Info transmission & & & $\begin{array}{c}0.063 \\
(1.143)\end{array}$ & $\begin{array}{c}0.089 \\
(1.639)\end{array}$ \\
\hline Initial IMF \& WB loans x Openness & & & $\begin{array}{l}0.007^{* *} \\
(2.531)\end{array}$ & $\begin{array}{l}0.006^{* *} \\
(2.142)\end{array}$ \\
\hline Initial IMF \& WB loans x Scope & & & $\begin{array}{l}0.465^{* *} \\
(2.436)\end{array}$ & $\begin{array}{l}0.469^{* *} \\
(2.191)\end{array}$ \\
\hline Initial IMF \& WB loans x UNGA voting & & & $\begin{array}{c}-10.894^{* *} \\
(-2.137)\end{array}$ & $\begin{array}{c}-11.135^{* *} \\
(-2.048)\end{array}$ \\
\hline Constant & $\begin{array}{l}17.095 \\
(0.954)\end{array}$ & $\begin{array}{l}25.804 \\
(1.381)\end{array}$ & $\begin{array}{l}-0.333 \\
(-0.164)\end{array}$ & $\begin{array}{l}20.873 \\
(1.112)\end{array}$ \\
\hline Observations & 591 & 544 & 574 & 544 \\
\hline R-squared & 0.266 & 0.296 & 0.196 & 0.327 \\
\hline Number of countries & 93 & 90 & 98 & 90 \\
\hline
\end{tabular}

Notes: Robust t-statistics in parentheses: ${ }^{* * *} \mathrm{p}<0.01,{ }^{* *} \mathrm{p}<0.05,{ }^{*} \mathrm{p}<0.1$ 
Table 2: Growth in the restricted sample (average), 1982-2008, OLS

\begin{tabular}{|c|c|c|c|c|}
\hline & $(1)$ & $(2)$ & (3) & $(4)$ \\
\hline IMF \& WB loans & $\begin{array}{c}-0.001 \\
(-0.292)\end{array}$ & $\begin{array}{c}-0.003 \\
(-0.679)\end{array}$ & $\begin{array}{c}0.049^{* * *} \\
(3.089)\end{array}$ & $\begin{array}{c}0.044^{* * * *} \\
(2.674)\end{array}$ \\
\hline Information transmission & & $\begin{array}{c}0.098 \\
(1.100)\end{array}$ & $\begin{array}{c}-0.014 \\
(-0.148)\end{array}$ & $\begin{array}{c}0.079 \\
(0.727)\end{array}$ \\
\hline Openness & & $\begin{array}{c}0.016 \\
(1.435)\end{array}$ & $\begin{array}{c}0.020 \\
(1.463)\end{array}$ & $\begin{array}{c}0.005 \\
(0.385)\end{array}$ \\
\hline Scope & & $\begin{array}{c}-0.043 \\
(-0.527)\end{array}$ & $\begin{array}{l}-0.304^{* *} \\
(-2.116)\end{array}$ & $\begin{array}{c}-0.361^{* *} \\
(-2.519)\end{array}$ \\
\hline UNGA voting & & $\begin{array}{c}-0.538 \\
(-0.089)\end{array}$ & $\begin{array}{l}11.831^{*} \\
(1.698)\end{array}$ & $\begin{array}{l}10.992 \\
(1.455)\end{array}$ \\
\hline Initial per cap. GDP (log) & $\begin{array}{l}-2.958^{*} \\
(-1.820)\end{array}$ & $\begin{array}{c}-5.802^{* * *} \\
(-4.547)\end{array}$ & & $\begin{array}{c}-5.526^{* * *} \\
(-4.514)\end{array}$ \\
\hline Investment & $\begin{array}{c}0.131^{* * *} \\
(4.364)\end{array}$ & $\begin{array}{c}0.155^{* * *} \\
(4.863)\end{array}$ & & $\begin{array}{c}0.137^{* * *} \\
(4.169)\end{array}$ \\
\hline CPIA & $\begin{array}{c}2.061^{* * *} \\
(6.619)\end{array}$ & $\begin{array}{c}2.051^{* * *} \\
(6.286)\end{array}$ & & $\begin{array}{c}2.161^{* * *} \\
(6.570)\end{array}$ \\
\hline Life expectancy $(\log )$ & $\begin{array}{c}-3.556 \\
(-1.601)\end{array}$ & $\begin{array}{l}-5.200^{* *} \\
(-2.533)\end{array}$ & & $\begin{array}{c}-5.533^{* * *} \\
(-2.666)\end{array}$ \\
\hline Life fertility (log) & $\begin{array}{c}-1.010 \\
(-0.293)\end{array}$ & $\begin{array}{l}1.309 \\
(0.328)\end{array}$ & & $\begin{array}{l}1.827 \\
(0.457)\end{array}$ \\
\hline Democracy & $\begin{array}{c}0.013 \\
(0.355)\end{array}$ & $\begin{array}{c}0.020 \\
(0.527)\end{array}$ & & $\begin{array}{c}0.007 \\
(0.177)\end{array}$ \\
\hline IMF \& WB loans x Info transmission & & & $\begin{array}{c}-0.000 \\
(-0.035)\end{array}$ & $\begin{array}{c}0.000 \\
(0.503)\end{array}$ \\
\hline IMF \& WB loans x Openness & & & $\begin{array}{c}0.000^{* * * *} \\
(3.453)\end{array}$ & $\begin{array}{c}0.000^{* * *} \\
(3.436)\end{array}$ \\
\hline IMF \& WB loans $x$ Scope & & & $\begin{array}{l}0.005^{* *} \\
(2.347)\end{array}$ & $\begin{array}{l}0.005^{* *} \\
(2.254)\end{array}$ \\
\hline IMF \& WB loans x UNGA voting & & & $\begin{array}{c}-0.188^{* * *} \\
(-3.460)\end{array}$ & $\begin{array}{c}-0.197^{* * *} \\
(-3.384)\end{array}$ \\
\hline Constant & $\begin{array}{l}21.698 \\
(1.245)\end{array}$ & $\begin{array}{c}30.669^{*} \\
(1.689)\end{array}$ & $\begin{array}{c}-1.187 \\
(-0.569)\end{array}$ & $\begin{array}{l}25.095 \\
(1.374)\end{array}$ \\
\hline Observations & 591 & 544 & 574 & 544 \\
\hline R-squared & 0.257 & 0.285 & 0.181 & 0.324 \\
\hline Number of id & 93 & 90 & 98 & 90 \\
\hline
\end{tabular}

Robust t-statistics in parentheses: ${ }^{* * *} \mathrm{p}<0.01,{ }^{* *} \mathrm{p}<0.05,{ }^{*} \mathrm{p}<0.1$ 
Table 3: Growth in the restricted sample (average lagged), 1982-2008, OLS

\begin{tabular}{|c|c|c|c|c|}
\hline & $(1)$ & $(2)$ & $(3)$ & $(4)$ \\
\hline IMF \& WB loans $(-1)$ & $\begin{array}{c}0.020^{* * * *} \\
(4.390)\end{array}$ & $\begin{array}{c}0.020^{* * *} \\
(4.682)\end{array}$ & $\begin{array}{c}0.011 \\
(0.711)\end{array}$ & $\begin{array}{c}0.013 \\
(0.894)\end{array}$ \\
\hline Information transmission $(-1)$ & & $\begin{array}{c}0.072 \\
(1.024)\end{array}$ & $\begin{array}{l}-0.090 \\
(-1.309)\end{array}$ & $\begin{array}{l}-0.070 \\
(-1.054)\end{array}$ \\
\hline Openness (-1) & & $\begin{array}{c}0.011 \\
(0.712)\end{array}$ & $\begin{array}{c}0.020 \\
(1.131)\end{array}$ & $\begin{array}{c}0.020 \\
(1.130)\end{array}$ \\
\hline Scope $(-1)$ & & $\begin{array}{c}0.016 \\
(0.191)\end{array}$ & $\begin{array}{c}0.118 \\
(0.991)\end{array}$ & $\begin{array}{c}0.070 \\
(0.579)\end{array}$ \\
\hline UNGA voting $(-1)$ & & $\begin{array}{l}-8.304^{*} \\
(-1.862)\end{array}$ & $\begin{array}{l}-7.650 \\
(-1.332)\end{array}$ & $\begin{array}{l}-9.759^{*} \\
(-1.733)\end{array}$ \\
\hline Initial per cap. GDP (log) & $\begin{array}{l}-2.753 \\
(-1.603)\end{array}$ & $\begin{array}{l}-3.554^{* *} \\
(-2.193)\end{array}$ & & $\begin{array}{l}-3.426^{* *} \\
(-2.202)\end{array}$ \\
\hline Investment & $\begin{array}{c}0.116^{* * * *} \\
(3.993)\end{array}$ & $\begin{array}{c}0.114^{* * *} \\
(3.759)\end{array}$ & & $\begin{array}{c}0.118^{* * *} \\
(3.743)\end{array}$ \\
\hline CPIA & $\begin{array}{c}2.025^{* * *} \\
(6.033)\end{array}$ & $\begin{array}{c}2.001^{* * *} \\
(6.225)\end{array}$ & & $\begin{array}{c}2.019^{* * * *} \\
(6.436)\end{array}$ \\
\hline Life expectancy $(\log )$ & $\begin{array}{c}-2.493 \\
(-1.100)\end{array}$ & $\begin{array}{c}-1.554 \\
(-0.694)\end{array}$ & & $\begin{array}{c}-0.427 \\
(-0.206)\end{array}$ \\
\hline Life fertility $(\log )$ & $\begin{array}{c}-1.870 \\
(-0.427)\end{array}$ & $\begin{array}{c}-1.533 \\
(-0.367)\end{array}$ & & $\begin{array}{c}-1.515 \\
(-0.379)\end{array}$ \\
\hline Democracy & $\begin{array}{l}-0.034 \\
(-0.945)\end{array}$ & $\begin{array}{c}-0.033 \\
(-0.879)\end{array}$ & & $\begin{array}{l}-0.032 \\
(-0.897)\end{array}$ \\
\hline IMF \& WB loans $x$ Info transmission $(-1)$ & & & $\begin{array}{l}0.002^{* *} \\
(2.332)\end{array}$ & $\begin{array}{l}0.003^{* * * *} \\
(2.955)\end{array}$ \\
\hline IMF \& WB loans x Openness $(-1)$ & & & $\begin{array}{l}-0.000 \\
(-1.255)\end{array}$ & $\begin{array}{l}-0.000^{*} \\
(-1.899)\end{array}$ \\
\hline IMF \& WB loans x Scope $(-1)$ & & & $\begin{array}{c}-0.001 \\
(-0.756)\end{array}$ & $\begin{array}{c}-0.001 \\
(-0.883)\end{array}$ \\
\hline IMF \& WB loans x UNGA voting (-1) & & & $\begin{array}{c}0.024 \\
(0.513)\end{array}$ & $\begin{array}{c}0.020 \\
(0.385)\end{array}$ \\
\hline Constant & $\begin{array}{l}22.354 \\
(1.070)\end{array}$ & $\begin{array}{l}25.971 \\
(1.305)\end{array}$ & $\begin{array}{l}3.963^{* *} \\
(2.081)\end{array}$ & $\begin{array}{l}23.853 \\
(1.245)\end{array}$ \\
\hline Observations & 530 & 525 & 572 & 525 \\
\hline R-squared & 0.272 & 0.284 & 0.194 & 0.317 \\
\hline Number of countries & 93 & 90 & 99 & 90 \\
\hline
\end{tabular}

Robust t-statistics in parentheses: ${ }^{* * *} \mathrm{p}<0.01,{ }^{* *} \mathrm{p}<0.05,{ }^{*} \mathrm{p}<0.1$ 
Table 4: Growth in the full sample (initial values), 1982-2008, OLS

\begin{tabular}{|c|c|c|c|c|}
\hline & $(1)$ & $(2)$ & (3) & $(4)$ \\
\hline Initial IMF + WB loans & $\begin{array}{c}0.775 \\
(0.738)\end{array}$ & $\begin{array}{c}0.685 \\
(0.760)\end{array}$ & $\begin{array}{l}-11.864 \\
(-0.738)\end{array}$ & $\begin{array}{c}-42.748^{* * *} \\
(-3.418)\end{array}$ \\
\hline Initial IMF \& WB loans & $\begin{array}{c}0.274 \\
(0.298)\end{array}$ & $\begin{array}{c}0.320 \\
(0.423)\end{array}$ & $\begin{array}{l}14.709 \\
(0.937)\end{array}$ & $\begin{array}{c}45.285^{* * *} \\
(3.609)\end{array}$ \\
\hline dummy initial IMF\&WB & $\begin{array}{c}0.896 \\
(1.355)\end{array}$ & $\begin{array}{l}1.053^{*} \\
(1.740)\end{array}$ & $\begin{array}{c}-0.869 \\
(-0.300)\end{array}$ & $\begin{array}{l}-4.854^{*} \\
(-1.920)\end{array}$ \\
\hline Information transmission & & $\begin{array}{c}0.052 \\
(0.968)\end{array}$ & $\begin{array}{l}-0.149^{*} \\
(-1.714)\end{array}$ & $\begin{array}{c}0.033 \\
(0.625)\end{array}$ \\
\hline (dummy initial IMF\&WB) $x$ Info transmission & & & $\begin{array}{c}-0.060 \\
(-0.939)\end{array}$ & $\begin{array}{c}-0.057 \\
(-0.770)\end{array}$ \\
\hline (Initial IMF + WB loans) $x$ Information transmission & & & $\begin{array}{c}1.515 \\
(0.870)\end{array}$ & $\begin{array}{c}3.237^{* * *} \\
(3.252)\end{array}$ \\
\hline (Initial IMF \& WB loans ) $x$ Info transmission & & & $\begin{array}{l}-1.445 \\
(-0.840)\end{array}$ & $\begin{array}{c}-3.145^{* * *} \\
(-3.134)\end{array}$ \\
\hline Openness & & $\begin{array}{l}0.023^{* *} \\
(2.292)\end{array}$ & $\begin{array}{l}0.027^{*} \\
(1.801)\end{array}$ & $\begin{array}{c}0.010 \\
(0.884)\end{array}$ \\
\hline (dummy initial IMF\&WB) x Openness & & & $\begin{array}{l}0.022^{*} \\
(1.663)\end{array}$ & $\begin{array}{c}0.017 \\
(1.492)\end{array}$ \\
\hline (Initial IMF + WB loans) $x$ Openness & & & $\begin{array}{c}0.044 \\
(0.648)\end{array}$ & $\begin{array}{c}0.023 \\
(0.720)\end{array}$ \\
\hline (Initial IMF \& WB loans ) x Openness & & & $\begin{array}{c}-0.039 \\
(-0.589)\end{array}$ & $\begin{array}{c}-0.019 \\
(-0.604)\end{array}$ \\
\hline Scope & & $\begin{array}{c}-0.143 \\
(-1.400)\end{array}$ & $\begin{array}{l}-1.078^{* *} \\
(-2.554)\end{array}$ & $\begin{array}{l}-0.789^{* *} \\
(-2.307)\end{array}$ \\
\hline (dummy initial IMF\&WB) $\times$ Scope & & & $\begin{array}{l}0.819^{*} \\
(1.860)\end{array}$ & $\begin{array}{c}0.430 \\
(1.169)\end{array}$ \\
\hline (Initial IMF + WB loans) $\times$ Scope & & & $\begin{array}{c}1.855 \\
(1.529)\end{array}$ & $\begin{array}{l}-0.740 \\
(-0.884)\end{array}$ \\
\hline (Initial IMF \& WB loans ) x Scope & & & $\begin{array}{l}-1.446 \\
(-1.166)\end{array}$ & $\begin{array}{c}1.199 \\
(1.377)\end{array}$ \\
\hline UNGA voting & & $\begin{array}{c}-3.883 \\
(-0.681)\end{array}$ & $\begin{array}{l}-6.617 \\
(-1.031)\end{array}$ & $\begin{array}{l}-15.405 \\
(-1.510)\end{array}$ \\
\hline (dummy initial IMF\&WB) $x$ UNGA voting & & & $\begin{array}{l}-0.466 \\
(-0.048)\end{array}$ & $\begin{array}{c}17.760^{* *} \\
(2.119)\end{array}$ \\
\hline (Initial IMF + WB loans) $x$ UNGA voting & & & $\begin{array}{l}29.818 \\
(1.059)\end{array}$ & $\begin{array}{c}155.422^{* * *} \\
(3.616)\end{array}$ \\
\hline (Initial IMF \& WB loans ) x UNGA voting & & & $\begin{array}{l}-37.103 \\
(-1.343)\end{array}$ & $\begin{array}{c}-165.218^{* * *} \\
(-3.840)\end{array}$ \\
\hline Initial per cap. GDP (log) & $\begin{array}{l}-2.458^{*} \\
(-1.810)\end{array}$ & $\begin{array}{c}-5.173^{* * *} \\
(-5.162)\end{array}$ & & $\begin{array}{c}-5.148^{* * *} \\
(-5.204)\end{array}$ \\
\hline Investment & $\begin{array}{c}0.138^{* * *} \\
(4.755)\end{array}$ & $\begin{array}{c}0.154^{* * *} \\
(4.498)\end{array}$ & & $\begin{array}{c}0.137^{* * * *} \\
(4.201)\end{array}$ \\
\hline CPIA & $\begin{array}{c}2.035^{* * *} \\
(6.934)\end{array}$ & $\begin{array}{c}1.956^{* * *} \\
(6.282)\end{array}$ & & $\begin{array}{c}1.989^{* * * *} \\
(6.712)\end{array}$ \\
\hline Life expectancy $(\log )$ & $\begin{array}{l}-1.499 \\
(-0.893)\end{array}$ & $\begin{array}{l}-2.445 \\
(-1.617)\end{array}$ & & $\begin{array}{l}-2.074 \\
(-1.433)\end{array}$ \\
\hline Life fertility $(\log )$ & $\begin{array}{l}-1.008 \\
(-0.307)\end{array}$ & $\begin{array}{c}0.983 \\
(0.293)\end{array}$ & & $\begin{array}{c}2.337 \\
(0.668)\end{array}$ \\
\hline Democracy & $\begin{array}{l}-0.008 \\
(-0.218)\end{array}$ & $\begin{array}{l}-0.001 \\
(-0.032)\end{array}$ & & $\begin{array}{l}-0.023 \\
(-0.617)\end{array}$ \\
\hline Constant & $\begin{array}{l}15.835 \\
(1.000) \\
\end{array}$ & $\begin{array}{r}24.508 \\
(1.548) \\
\end{array}$ & $\begin{array}{c}3.158 \\
(1.400) \\
\end{array}$ & $\begin{array}{l}22.690 \\
(1.401) \\
\end{array}$ \\
\hline Observations & 763 & 700 & 814 & 700 \\
\hline R-squared & 0.270 & 0.297 & 0.267 & 0.361 \\
\hline Number of countries & 105 & 103 & 116 & 103 \\
\hline
\end{tabular}

Robust t-statistics in parentheses: ${ }^{* * *} \mathrm{p}<0.01,{ }^{* *} \mathrm{p}<0.05,{ }^{*} \mathrm{p}<0.1$ 


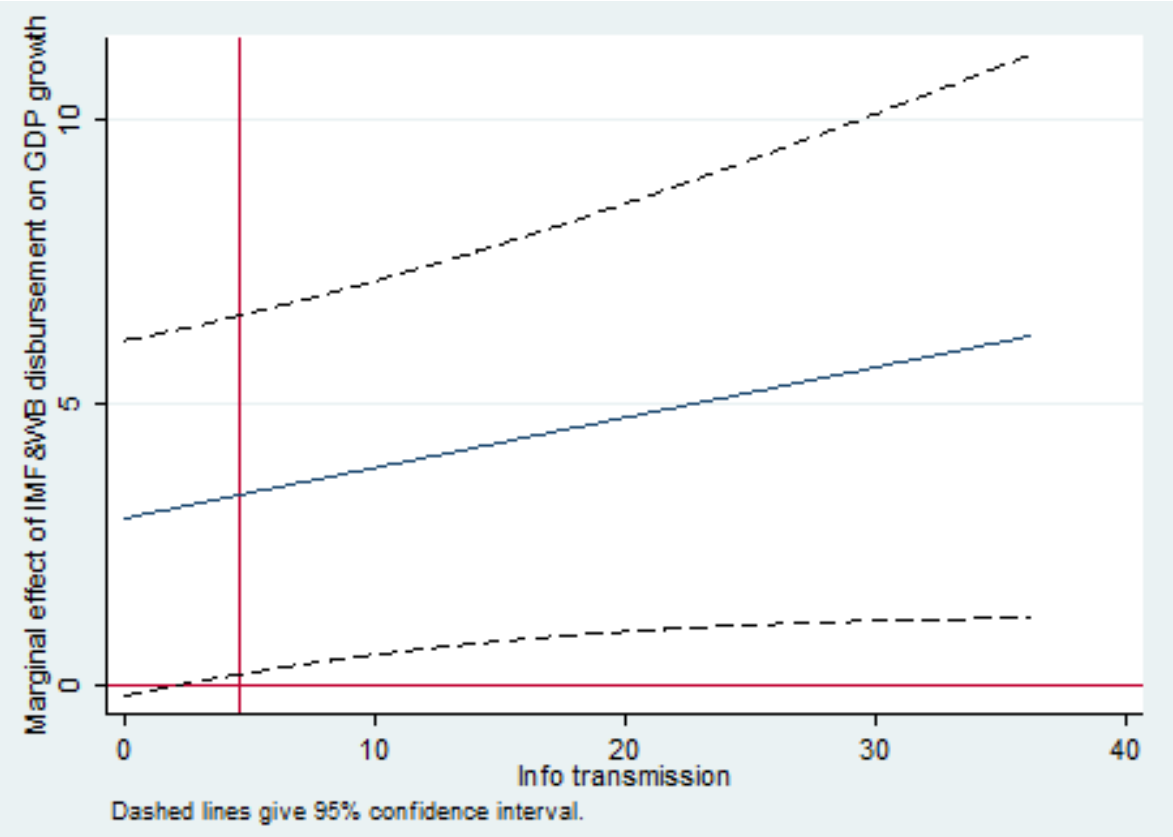

Figure 1: Marginal effect of initial values of IMF and WB loans on growth for different levels of Information Transmission (Table 1). The dashed line shows the 95\%-confidence interval.

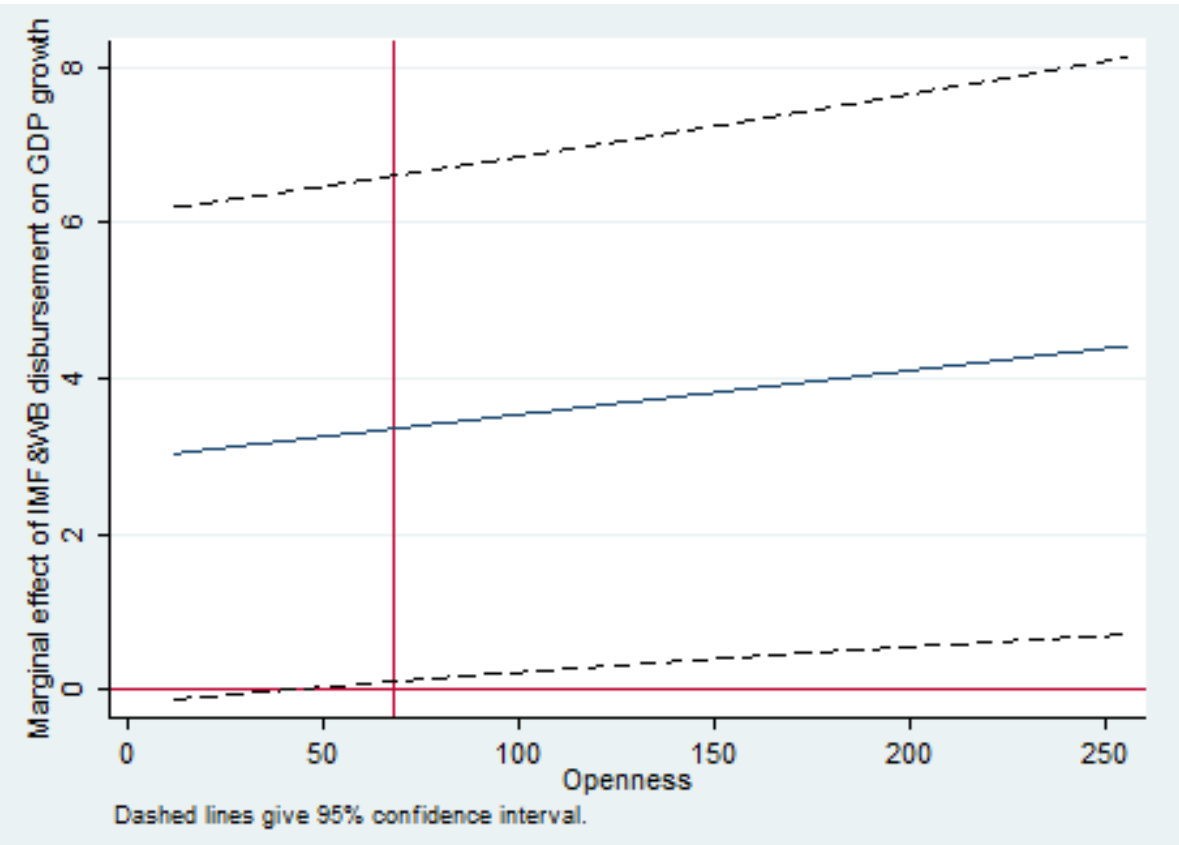

Figure 2: Marginal effect of initial values of IMF and WB loans on growth for different levels of Openness (Table 1). The dashed line shows the 95\%-confidence interval. 


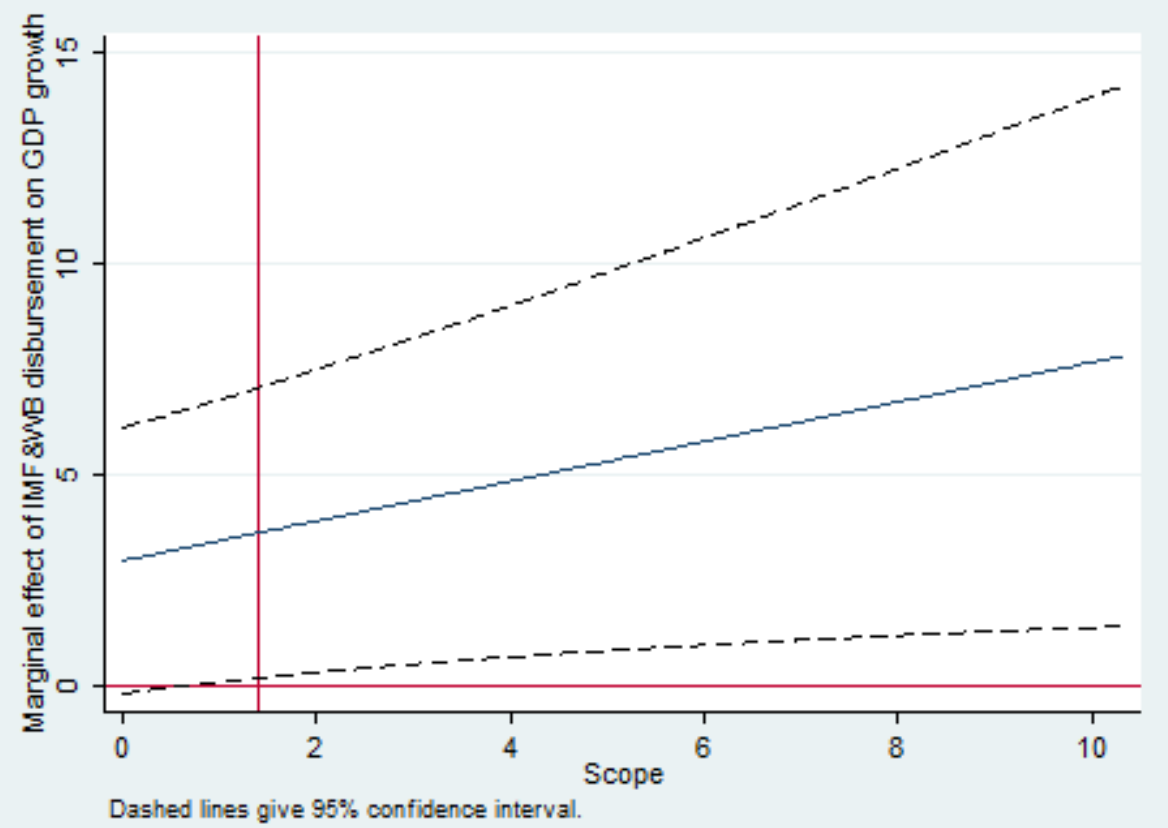

Figure 3: Marginal effect of initial values of IMF and WB loans on growth for different levels of Scope (Table 1). The dashed line shows the 95\%-confidence interval.

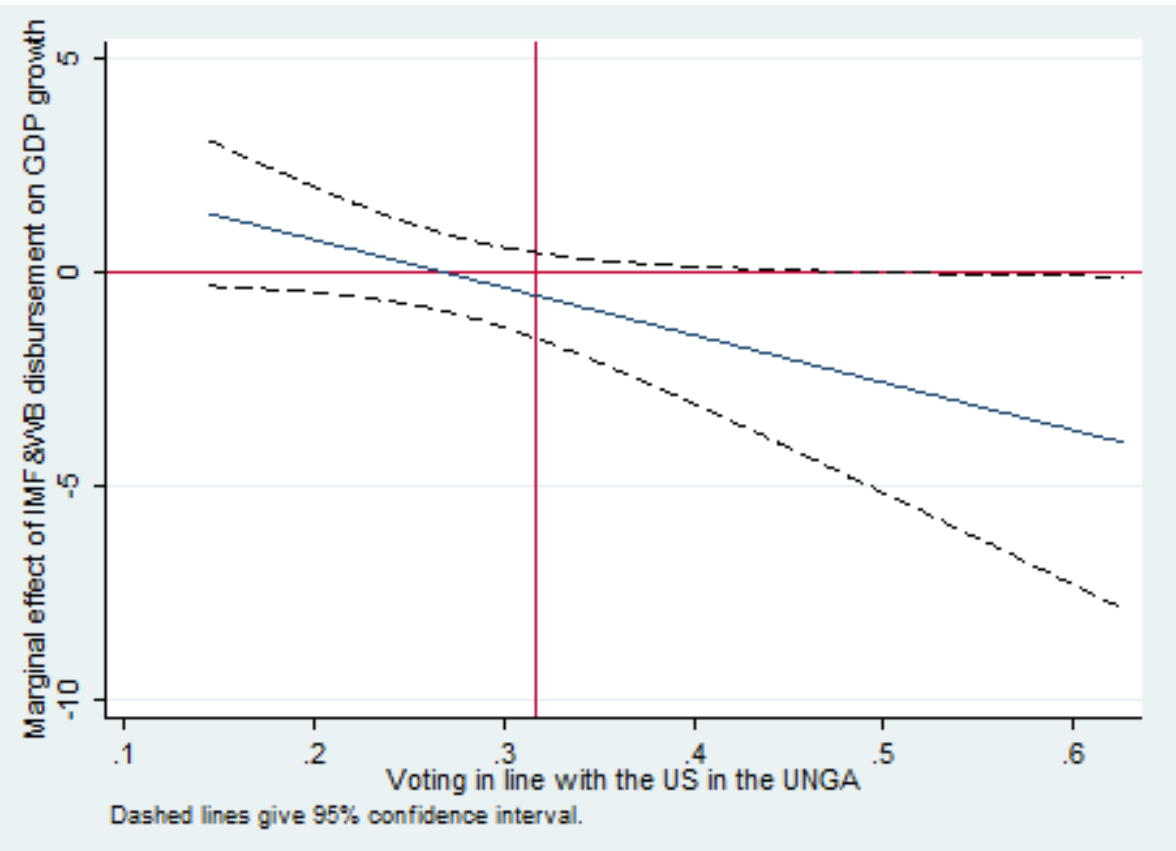

Figure 4: : Marginal effect of initial values of IMF and WB loans on growth for different levels of Voting in line with the U.S. in the U.N.G.A. (Table 1). The dashed line shows the $95 \%$-confidence interval. 


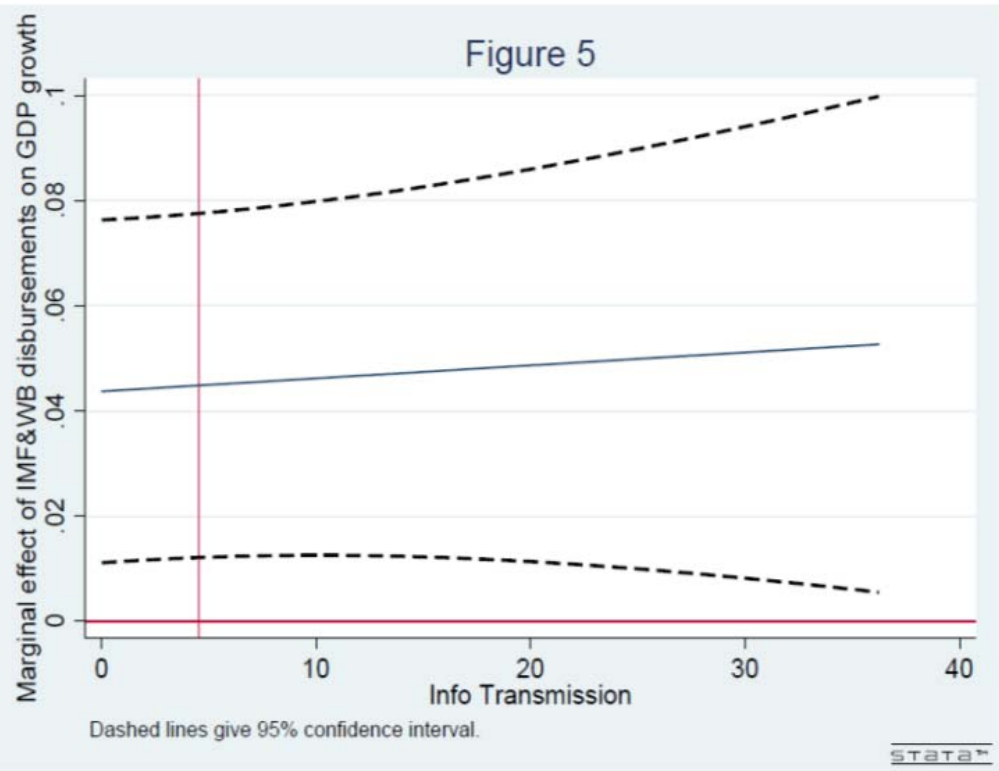

Figure 5: Marginal effect of average IMF and WB loans on growth for different levels of Information Transmission (Table 2). The dashed line shows the 95\%-confidence interval.

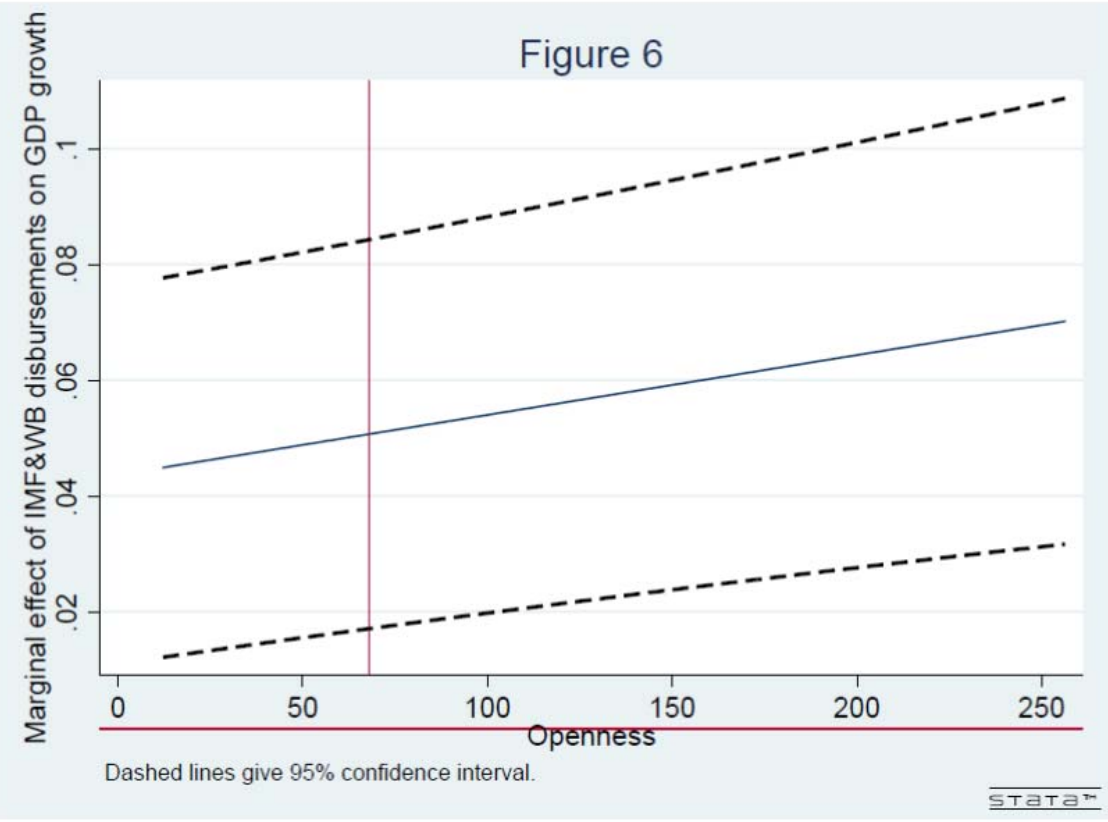

Figure 6: Marginal effect of average IMF and WB loans on growth for different levels of Openness (Table 2). The dashed line shows the 95\%-confidence interval. 


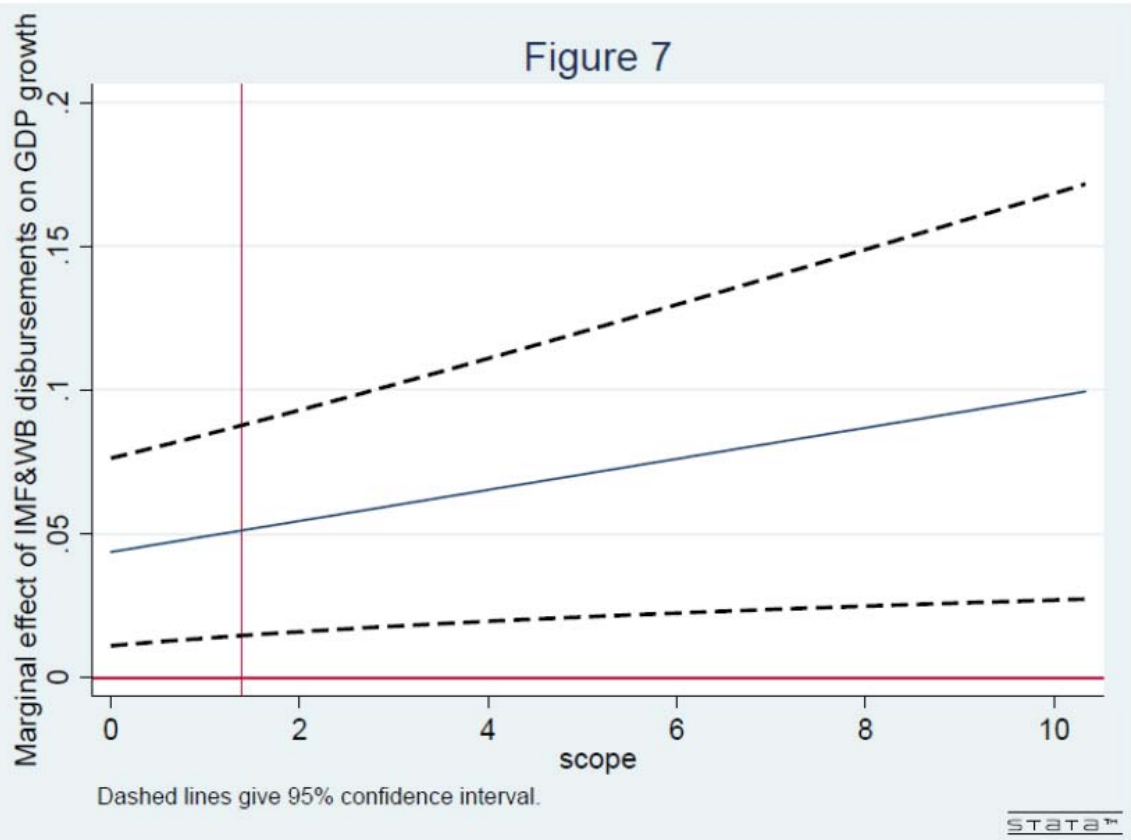

Figure 7: Marginal effect of average IMF and WB loans on growth for different levels of Scope (Table 2). The dashed line shows the 95\%-confidence interval.

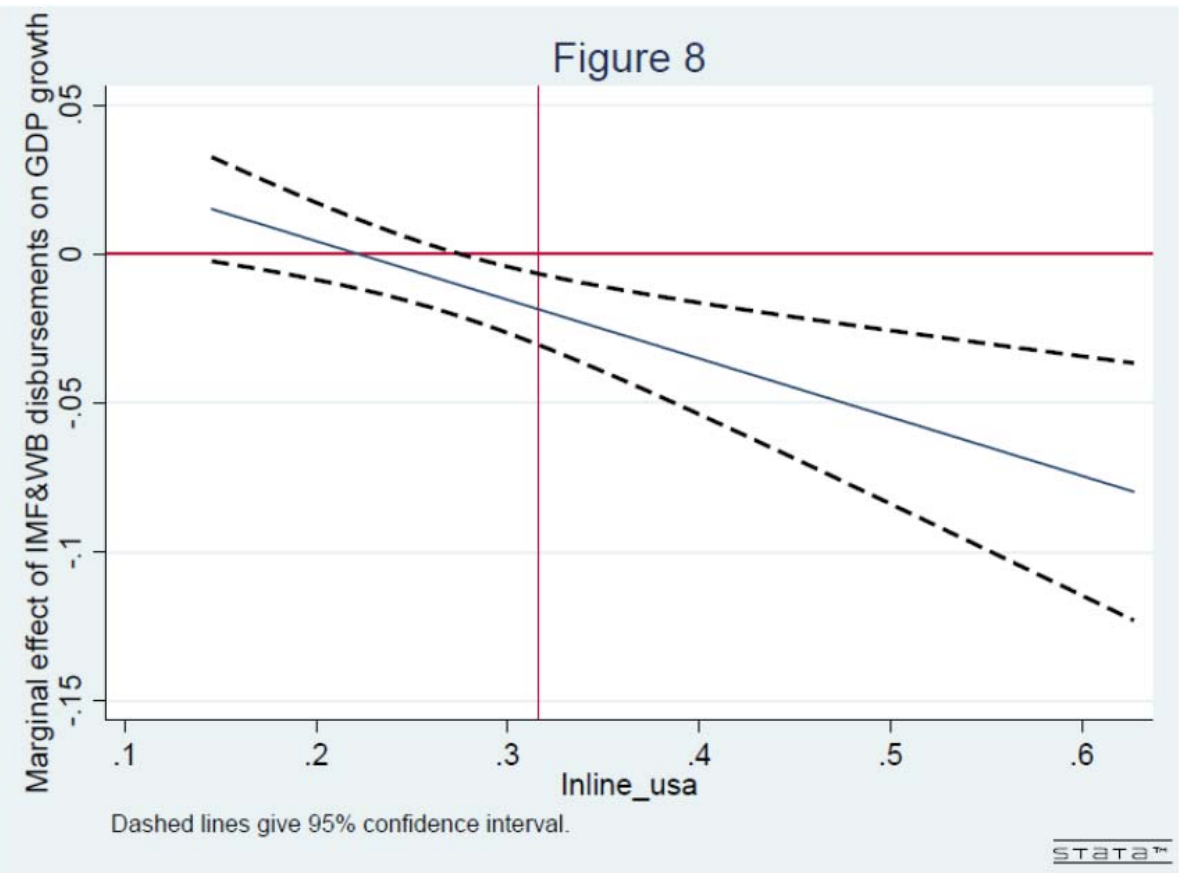

Figure 8: Marginal effect of average IMF and WB loans on growth for different levels of Voting in line with the U.S. in the U.N.G.A. (Table 2). The dashed line shows the 95\%-confidence interval. 


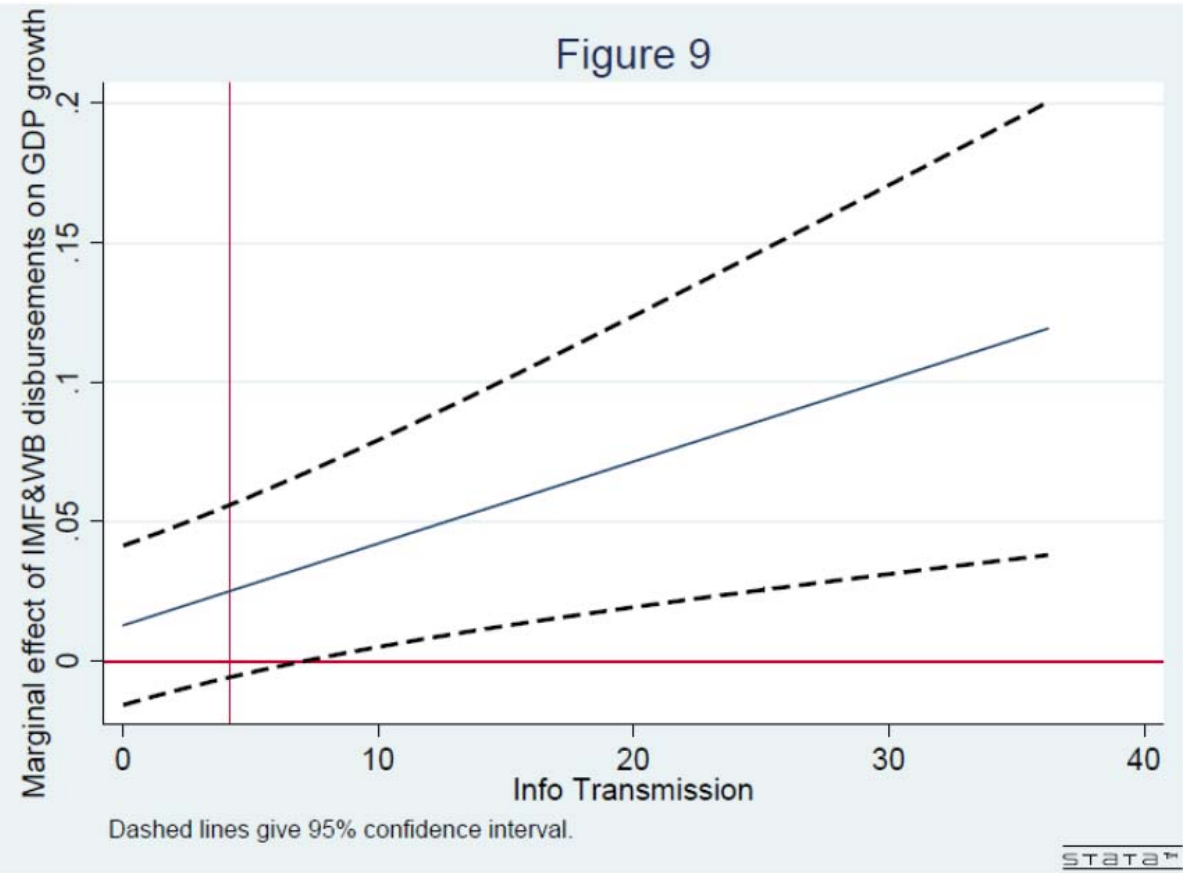

Figure 9: Marginal effect of (lagged) average IMF and WB loans on growth for different levels of Information Transmission (Table 3). The dashed line shows the 95\%-confidence interval. 


\section{Appendices}

\section{Appendix A}

Proof. of Proposition 1.

It is immediate to verify that substituting (9) and (15) in (17) we obtain $S L=\frac{\delta}{(1+2 \delta)^{2}}$. Taking the derivative with respect to $\delta$ we find that $\frac{\partial S L}{\partial \delta}>0$, for $0<\delta<\frac{1}{2}$, while $\frac{\partial S L}{\partial \delta}<0$, for $\delta>\frac{1}{2}$. Moreover, as $\delta \rightarrow \infty, S L \rightarrow 0$.

Proof. of Proposition 2.

Substituting (7), (9) and (15) in (17) we verify that $C L$ is equal to

$$
C L=S B
$$

where

$$
S=\frac{\delta+1}{7 \delta+4}
$$

is the residual variance (obtained after normalizing the environment volatility to 1 ), which measures the accuracy of information after receiving the messages, and

$$
B=\frac{1}{2} \delta(4 \delta+1) \frac{6 \delta+2 \delta^{2}+3}{(\delta+1)^{2}(2 \delta+1)^{2}}
$$

measures the value of communication.

As $\delta \rightarrow 0, S \rightarrow \frac{1}{4}$ and $B \rightarrow 0$, which means that although strategic uncertainty is at its maximum, $C L$ will not be relevant since information transmission is not valuable. As $\delta$ increases, however, communication becomes more and more valuable. Indeed, taking the limit of (A1) for $\delta \rightarrow \infty$, we can verify that the value of the parameter $B$ increases up to 1 . Conversely, the quality of communication improves as $\delta$ increases (i.e., $S$ starts decreasing). Initially, the first effect prevails, and the loss due to strategic communication increases, but eventually the positive effect of a more accurate communication becomes dominant and $C L$ starts decreasing although it always remains bounded away from zero. Indeed, we can see that as $\delta \rightarrow \infty, S \rightarrow \frac{1}{7}$ implying that information transmission will never achieve perfection. 
Appendix B: List of countries included in the sample

\begin{tabular}{|c|c|c|}
\hline Sub-Saharan Africa & Maldives & Bulgaria \\
\hline Angola & Nepal & Croatia \\
\hline Benin & Pakistan & Georgia \\
\hline Botswana & Sri Lanka & Hungary \\
\hline Burkina Faso & Middle East and North Africa & Kazakhstan \\
\hline Burundi & Algeria & Kyrgyz Republic \\
\hline Cameroon & Djibouti & Latvia \\
\hline Cape Verde & Egypt, Arab Rep. & Lithuania \\
\hline Central African Republic & Iran, Islamic Rep. & Macedonia, FYR \\
\hline Chad & Jordan & Moldova \\
\hline Comoros & Lebanon & Poland \\
\hline Congo, Dem. Rep. & Morocco & Romania \\
\hline Congo, Rep. & Oman & Russian Federation \\
\hline Cote d'Ivoire & Syrian Arab Republic & Serbia \\
\hline Equatorial Guinea & Tunisia & Slovak Republic \\
\hline Eritrea & Yemen, Rep. & Tajikistan \\
\hline Ethiopia & Latina America and Caribbean & Turkey \\
\hline Gabon & Argentina & Ukraine \\
\hline Gambia, The & Belize & East Asia and Pacific \\
\hline Ghana & Bolivia & Cambodia \\
\hline Guinea & Brazil & China \\
\hline Guinea-Bissau & Chile & Fiji \\
\hline Kenya & Colombia & Indonesia \\
\hline Lesotho & Costa Rica & Lao PDR \\
\hline Liberia & Dominica & Malaysia \\
\hline Madagascar & Dominican Republic & Mongolia \\
\hline Malawi & Ecuador & Papua New Guinea \\
\hline Mali & El Salvador & Philippines \\
\hline Mauritania & Grenada & Samoa \\
\hline Mauritius & Guatemala & Solomon Islands \\
\hline Mozambique & Guyana & Thailand \\
\hline Niger & Haiti & Tonga \\
\hline Nigeria & Honduras & Vanuatu \\
\hline Rwanda & Jamaica & Vietnam \\
\hline Sao Tome and Principe & Mexico & \\
\hline Senegal & Nicaragua & \\
\hline Seychelles & Panama & \\
\hline Sierra Leone & Paraguay & \\
\hline South Africa & Peru & \\
\hline Sudan & St. Kitts and Nevis & \\
\hline Swaziland & St. Lucia & \\
\hline Tanzania & St. Vincent and the Grenadines & \\
\hline Togo & Uruguay & \\
\hline Uganda & Venezuela, RB & \\
\hline Zambia & Europe and Central Asia & \\
\hline Zimbabwe & Albania & \\
\hline South Asia & Armenia & \\
\hline Bangladesh & Azerbaijan & \\
\hline Bhutan & Belarus & \\
\hline India & Bosnia and Herzegovina & \\
\hline
\end{tabular}




\begin{tabular}{|c|c|c|}
\hline Variable & Definition & Source \\
\hline \multicolumn{3}{|l|}{ DEPENDENT VARIABLE } \\
\hline GDP growth & Per capita GDP (constant 2000 US\$) & WDI (2008) \\
\hline \multicolumn{3}{|l|}{ VARIABLES OF INTEREST } \\
\hline $\mathrm{IMF}+\mathrm{WB}$ loans & Sum of IMF and WB loans (ratio to GDP) & WDI (2008) \\
\hline dIMF\&WB & dummy $=1$ in case of IMF-WB joint participation & Built by authors \\
\hline IMF \& WB loans & Sum of IMF and WB loans interacted with dIMF\&WB & Built by authors \\
\hline IMF \& WB loans $x$ Info transmission & IMF \& WB loans interacted with Info transmission & Built by authors \\
\hline IMF \& WB loans x Openness & IMF \& WB loans interacted with Openness & Built by authors \\
\hline IMF \& WB loans x Scope & IMF \& WB loans interacted with Scope & Built by authors \\
\hline IMF \& WB loans x UNGA voting & IMF \& WB loans interacted with voting with US in UNGA & Built by authors \\
\hline \multicolumn{3}{|l|}{ CONTROL VARIABLES } \\
\hline Initial per cap. GDP $(\log )$ & Log of per capita GDP at the beginning of the period & WDI (2008) \\
\hline Investment & Gross fixed capital formation (ratio to GDP) & WDI (2008) \\
\hline Openness & Export + Import of goods and services & WDI (2008) \\
\hline CPIA & Country Policy and Institutional Assessment & World Bank \\
\hline Life fertility (log) & Fertility rate (birth per woman) & WDI (2008) \\
\hline Life exp. (log) & Log of life expectancy & WDI (2008) \\
\hline Democracy & Polity2 score taken from the Polity IV dataset & Marshall and Jaggers (2009) \\
\hline Info transmission & Fixed telephone lines per 100 inhabitants & World Telecommunication database \\
\hline Scope & Areas covered by Conditions & | IMF's MONA database (2008) \\
\hline UNGA voting & Percentage of votes within a year inline with the US in the UNGA & Dreher et al. (2009) \\
\hline
\end{tabular}


Appendix D: Descriptive statistics (Estimation sample of Table 1 and Table 3)

\begin{tabular}{|c|c|c|c|c|}
\hline Variable & Mean & $\mathrm{SD}$ & Min & Max \\
\hline Per capita growth & 1.14 & 3.8 & -14.42 & 14.84 \\
\hline Initial IMF \& WB loans & 0.62 & 0.63 & 0.01 & 5.29 \\
\hline Average IMF \& WB loans & 0.04 & 0.06 & 0.00 & 0.51 \\
\hline Information transmission & 4.53 & 6.94 & 0.02 & 36.24 \\
\hline Openness & 67.9 & 36.25 & 12.23 & 256.3 \\
\hline Scope & 1.38 & 2.17 & 0 & 10.33 \\
\hline UNGA voting & 0.32 & 0.09 & 0.15 & 0.63 \\
\hline Initial per cap. GDP (log) & 6.45 & 1.04 & 4.43 & 8.99 \\
\hline Investment & 20.44 & 7.43 & 2.56 & 62.02 \\
\hline CPIA & 3.1 & 0.64 & 1 & 4.9 \\
\hline Life expectancy (log) & 1.44 & 0.46 & 0.09 & 2.11 \\
\hline Life fertility (log) & 4.06 & 0.18 & 3.33 & 4.34 \\
\hline Democracy & 0.89 & 6.32 & -10 & 10 \\
\hline
\end{tabular}

